\title{
Control of Cardiac Function in vivo with a Light-Regulated Drug
}

Fabio Riefolo, Carlo Matera, Aida Garrido-Charles, Alexandre M. J. Gomila, Luca Agnetta, Enrique Claro, Roser Masgrau, Ulrike Holzgrabe, Montserrat Batlle, Michael Decker, Eduard Guasch, Pau Gorostiza Submitted date: 04/03/2019 Posted date: 04/03/2019

Licence: CC BY-NC-ND 4.0

Citation information: Riefolo, Fabio; Matera, Carlo; Garrido-Charles, Aida; Gomila, Alexandre M. J.; Agnetta, Luca; Claro, Enrique; et al. (2019): Control of Cardiac Function in vivo with a Light-Regulated Drug. ChemRxiv. Preprint.

Remote control of physiological functions with light offers the promise of unveiling their complex spatiotemporal dynamics in vivo, and enabling highly focalized therapeutic interventions with reduced systemic toxicity. Optogenetic methods have been implemented in the heart, but the need of genetic manipulation jeopardizes clinical applicability. This study aims at developing, testing and validating the first light-regulated drug with cardiac effects, in order to avoid the requirement of genetic manipulation offered by optogenetic methods. A M2 muscarinic acetylcholine receptors (mAChRs) light-regulated drug (PAI) was designed, synthesized and pharmacologically characterized. The design was based on the orthosteric mAChRs agonist Iperoxo, an allosteric M2 ligand, and a photoswitchable azobenzene linker. PAI can be reversibly photoisomerized between cis and trans configurations under ultraviolet (UV) and visible light, respectively, and it reversibly photoswitches the activity of M2 muscarinic acetylcholine receptors. We have evaluated in vitro photoresponses using a calcium imaging assay in genetically unmodified receptors overexpressed in mammalian cells. Furthermore, using this new chemical tool, we demonstrate for the first time photoregulation of cardiac function in vivo in wildtype frog tadpoles and in rats with a method that does not require genetic manipulation. Such a new approach may enable enhanced spatial and temporal selectivity for cardiovascular drugs.

File list (3)

Control of cardiac function in vivo with a light-regulated d... (679.51 KiB) view on ChemRxiv • download file Control of cardiac function in vivo with a light-regulated dru... (4.50 MiB) view on ChemRxiv • download file 


\title{
Control of cardiac function in vivo with a light-regulated drug
}

\author{
Fabio Riefolo ${ }^{1,2, \ddagger}$, Carlo Matera ${ }^{1,2, \ddagger}$, Aida Garrido-Charles ${ }^{1,2}$, Alexandre M. J. Gomila ${ }^{1,2}$, Luca Agnetta ${ }^{3}$, \\ Enrique Claro ${ }^{4}$, Roser Masgrau ${ }^{4}$, Ulrike Holzgrabe ${ }^{3}$, Montserrat Batlle ${ }^{5}$, Michael Decker ${ }^{3}$, Eduard \\ Guasch $^{5,6}$, and Pau Gorostiza ${ }^{1,2,7, *}$ \\ ${ }^{1}$ Institute for Bioengineering of Catalonia (IBEC), Barcelona Institute for Science and Technology (BIST) \\ ${ }^{2}$ Network Biomedical Research Center in Bioengineering, Biomaterials, and Nanomedicine (CIBER-BBN) \\ ${ }^{3}$ Pharmaceutical and Medicinal chemistry, Institute of Pharmacy and Food Chemistry, Julius Maximilian University of \\ Würzburg, Am Hubland, D-97074 Würzburg, Germany \\ ${ }^{4}$ Institut de Neurociències (INc), and, Dept. Bioquímica i Biologia Molecular, Unitat de Bioquímica de Medicina, Universi- \\ tat Autònoma de Barcelona (UAB) \\ ${ }^{5}$ Cardiovascular Institute, Hospital Clinic; University of Barcelona (UB); IDIBAPS \\ ${ }^{6}$ Network Biomedical Research Center in Cardiovascular Diseases (CIBER-CV) \\ ${ }^{7}$ Catalan Institution for Research and Advanced Studies (ICREA) \\ (†) Contributed equally to this work. $(*)$ Corresponding author.
}

neuromodulation, cardiac photoregulation, cholinergic, muscarinic, photopharmacology, dualsteric agonist

\begin{abstract}
Remote control of physiological functions with light offers the promise of unveiling their complex spatiotemporal dynamics in vivo, and enabling highly focalized therapeutic interventions with reduced systemic toxicity. Optogenetic methods have been implemented in the heart, but the need of genetic manipulation jeopardizes clinical applicability. This study aims at developing, testing and validating the first light-regulated drug with cardiac effects, in order to avoid the requirement of genetic manipulation offered by optogenetic methods. A M2 muscarinic acetylcholine receptors (mAChRs) light-regulated drug (PAI) was designed, synthesized and pharmacologically characterized. The design was based on the orthosteric mAChRs agonist Iperoxo, an allosteric M2 ligand, and a photoswitchable azobenzene linker. PAI can be reversibly photoisomerized between cis and trans configurations under ultraviolet (UV) and visible light, respectively, and it reversibly photoswitches the activity of M2 muscarinic acetylcholine receptors. We have evaluated in vitro photoresponses using a calcium imaging assay in genetically unmodified receptors overexpressed in mammalian cells. Furthermore, using this new chemical tool, we demonstrate for the first time photoregulation of cardiac function in vivo in wildtype frog tadpoles and in rats with a method that does not require genetic manipulation. Such a new approach may enable enhanced spatial and temporal selectivity for cardiovascular drugs.
\end{abstract}

\section{INTRODUCTION}

Modern medical treatments are largely based on the ability of pharmacological drugs to interact with a molecular target in the human body (e.g., receptors, enzymes, ion channels, transporters) in order to evoke a physiological response. Most of such pharmacological targets are constitutively expressed throughout the human body in both healthy and diseased tissues: this leads to the impossibility of a truly selective interaction between drug and target in a disease state, and consequently give rise to undesired side effects and a limited dose efficacy of the molecule at the site of action. ${ }^{1,2}$ In order to focalize the drug action site and prevent systemic toxicity of medical treatments, new methods have been developed to switch on and off the pharmacological activity of small molecules with light. ${ }^{3-9}$ They can be used in combination with devices that deliver light to specific locations in the body ${ }^{10-13}$ in order to remotely control drug dosing and selectivity.

While spatiotemporal control of drug action site is an unmet need in many diseases, cardiopathies are paradigmatic of such requirements because of the rapid time course and complex integration of electrophysiological and molecular events in very specific areas of the heart. In particular, cardiac arrhythmias are often due to complex dysfunctions in multiple ionic channel currents at diverse locations. At present, most cardiac rhythm control strategies rely on antiarrhythmic drugs (AAD) targeting ionic currents, whose effects cannot be regulated spatiotemporally. As a result, AADs often give rise to intolerable side effects, including ventricular pro-arrhythmogenicity and systemic side effects, and are only partially effective. Overcoming the high failure and complication rates of current therapeutic strategies to treat these diseases will require both patient-personalized determination of the specific physiopathological mechanism, as well as qualitative pharmacological breakthroughs. ${ }^{14}$ The potential of light as a therapeutic tool with high spatial and temporal resolution has been recently investigated in the cardiovascular field, particularly for cardiac arrhythmias, through optogenetics, ${ }^{10,15-18}$ but its application to human subjects with therapeutic purposes is still hampered by safety, regulatory and economic hurdles.

Unlike optogenetics, light-regulated drugs can photocontrol endogenous receptors and channels without genetic manipulation. These compounds are small molecules that can be tested, validated and approved using standard drug development pro- 
cedures, and can be applied directly to wildtype organisms, including humans. In principle, light regulated AADs with desired pharmacological and electrophysiological properties could be timely activated when needed while minimizing unintended effects in other regions. The development of such pharmacological agents would bring forward new effective treatments for cardiovascular diseases and would also be very useful for research purposes. Light-regulated drugs are designed by chemically modifying a bioactive molecule of interest in order to introduce a photoswitch, which is a special molecular moiety that changes its configuration between two distinct thermodynamically stable forms upon illumination. ${ }^{3,9} \mathrm{Be}-$ cause the molecular structure directly affects the activity of a drug, the photo-induced structural change allows using light to remotely regulate its therapeutic action.

Cardiac function is controlled by the autonomic nervous system (i.e., the sympathetic and the parasympathetic nervous systems), which acts via adrenoceptors and muscarinic acetylcholine receptors (mAChRs), respectively. ${ }^{19}$ In particular, stimulation of $\beta 1$ and $\beta 2$ adrenergic receptors increases the heart rate (positive chronotropy) and contractility (positive in- otropy), whilst stimulation of $\mathrm{M} 2 \mathrm{mAChRs}$ decreases heart rate and prolongs the atrio-ventricular conduction time. ${ }^{20,21}$ Moreover, sustained parasympathetic activation yields a local anti-inflammatory effect in the ventricle. Thus, adrenergic and muscarinic receptors constitute suitable target candidates to control cardiac function with light.

Here, we target $\mathrm{mAChRs}$ and report the development of the first light-regulated drug that allows controlling cardiac function, providing in vitro and in vivo results that support this application. The compound, Phthalimide-Azo-Iperoxo (PAI), is a novel light-controlled muscarinic dualsteric agonist active in M2 mAChRs (Figure 1). The molecular design combines the structure of a known M2 muscarinic dualsteric agonist 22,23 with a photoswitchable azobenzene linker that enables toggling reversibly between biologically active and inactive states with light. We characterize PAI in vitro using recombinant M2 mAChRs, and in silico to investigate its putative binding modes. We also test PAI in frog tadpoles and in rats to demonstrate its potential as a light-regulated AAD to control cardiac function in vivo without genetic manipulations.
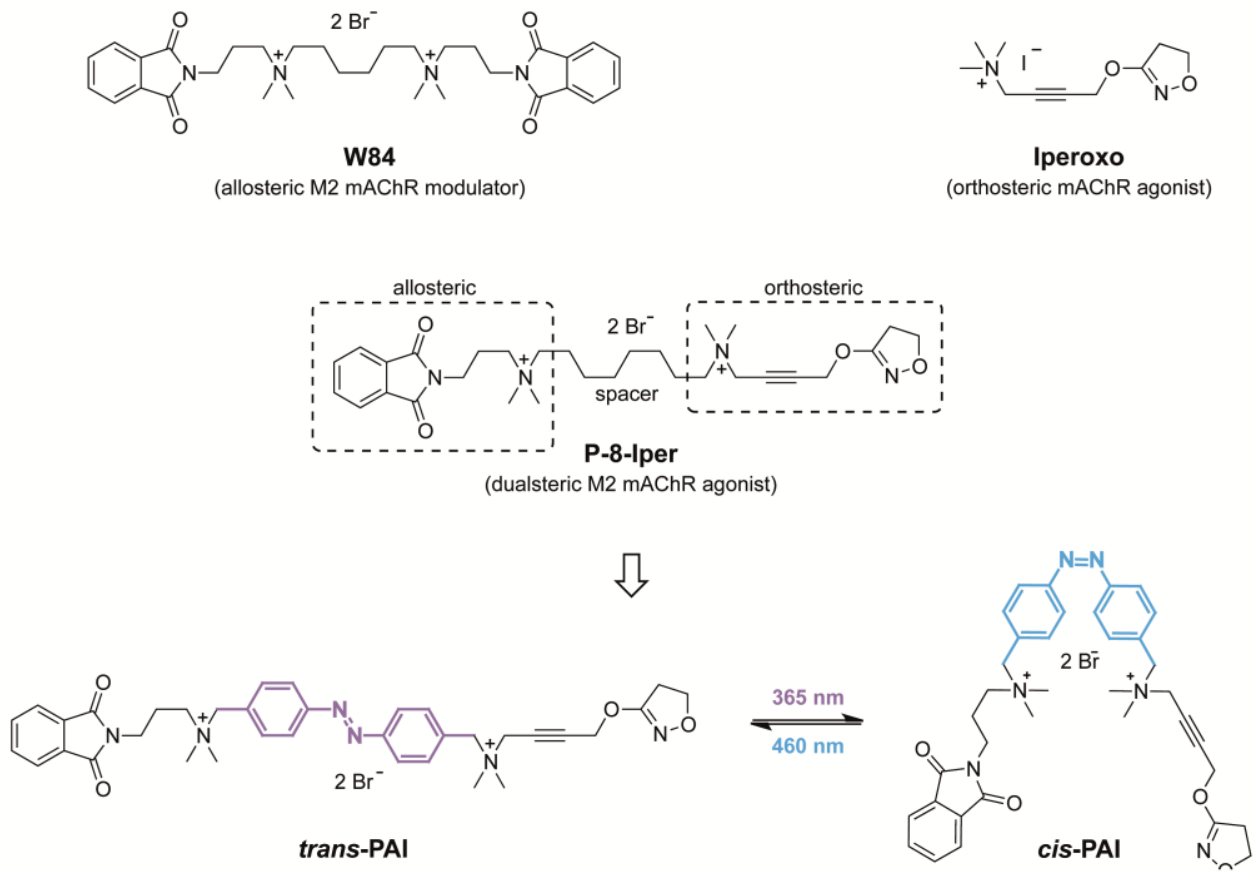

FIGURE 1. Chemical structures of the muscarinic ligands discussed in this work: the allosteric modulator W84, the orthosteric agonist Iperoxo, the dualsteric agonist P-8-Iper, and the photoswitchable dualsteric agonist PAI.

\section{RESULTS}

\section{Rational design, chemical synthesis and photochemical properties of PAI.}

Muscarinic acetylcholine receptors (mAChRs) belong to class A $\mathrm{G}$ protein-coupled receptors (GPCRs) and are divided in five different subtypes (M1-M5). ${ }^{24}$ M2 receptor is extensively expressed in the heart. All five $\mathrm{mAChRs}$ are characterized by a high sequence homology in the orthosteric site located in the transmembrane region. This fact limits the development of subtype-selective orthosteric agonists. On the other hand, the allosteric site located in the extracellular loop is less conserved, thus muscarinic allosteric agents are commonly endowed with a more pronounced subtype-selectivity. ${ }^{25}$

A chemical strategy commonly applied to overcome such limitation is the incorporation, within the same molecular structure, of two distinct pharmacophore elements belonging to (a) high-affinity/low-selectivity orthosteric agonists and (b) highly selective allosteric ligands, covalently connected through spacers of appropriate length. ${ }^{26-29}$ These hybrid ligands, termed "dualsteric" or "bitopic", are capable to bind simultaneously to both the orthosteric and the allosteric sites of mus- 
carinic receptors and are often endowed with valuable properties ${ }^{30}$, such as a certain receptor subtype selectivity, functional selectivity ("biased agonism") 22,28 and lower toxicity in vivo compared to their parent compounds. ${ }^{23}$ Moreover, such ligands bear in their structure two permanently charged nitrogen at- oms, which likely prevent them from crossing the blood-brain barrier. This property constrains their effects to the peripheral nervous system, which is advantageous in the case of drugs targeting the cardiovascular system.
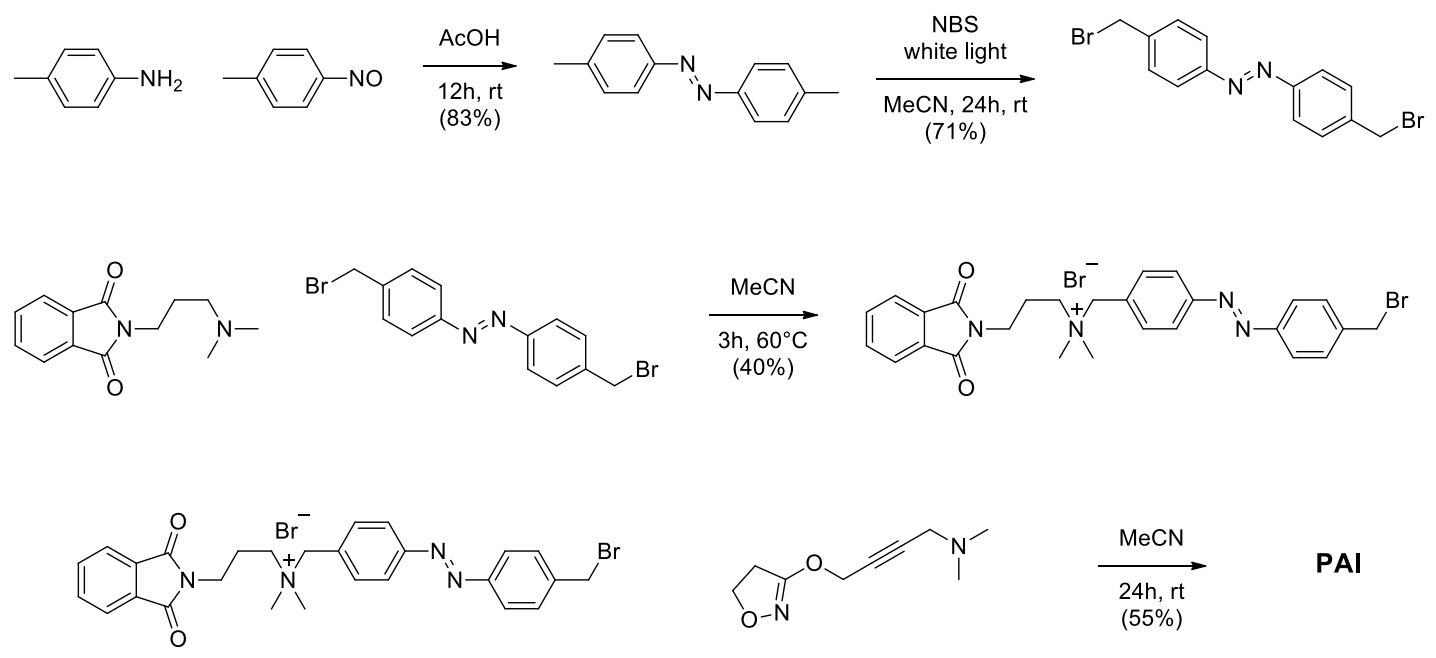

PAl

\section{Scheme 1. Chemical synthesis of PAI.}

Given the above mentioned favorable features of such dualsteric muscarinic agonists, we chose to follow a similar approach to build a new photoresponsive pharmacological tool, PAI (Figure 1), by replacing the typical polymethylene spacer chain of a known M2 dualsteric agonist (P-8-Iper) ${ }^{23}$ with an azobenzene linker to serve as molecular photoswitch. The orthosteric and allosteric moieties, deriving respectively from Iperoxo and W84, remained unchanged in PAI. A similar strategy to prepare a M1 muscarinic ligand was followed by some of the authors of this article and reported recently. ${ }^{31}$ The orthosteric and allosteric fragments were prepared as previously reported ${ }^{23,26-28}$ and connected through an azobenzene-based linker obtained from commercially available starting materials (Scheme 1, see also SI for details). PAI showed the typical $\mathrm{UV}-\mathrm{Vis}$ absorption spectrum and thermal stability of a conventional azobenzene. It can be isomerized to the cis form (about $73 \%$ conversion) by applying $365 \mathrm{~nm}$ light, while it thermally relaxes back to the trans form in several hours at room temperature. It can be also effectively back-isomerized to the trans form by applying white light or $460 \mathrm{~nm}$ blue light (Figure S2.1, S2.2 and S2.3).

The incorporation of a photo-isomerizable moiety into the structure of a dualsteric agonist enables controlling with light the mutual position of the orthosteric and the allosteric groups, presumably leading to differences between the two isomers in binding mode and efficacy. These effects were investigated using in vitro assays and computer simulations.

PAI allows reversible photo-activation of $\mathrm{M} 2 \mathrm{mAChRs}$ in calcium imaging experiments and molecular docking simulations.

To characterize the pharmacological properties of PAI, we first assessed in vitro its ability to reversibly activate M2 mAChRs in a light-dependent fashion. To this end, we performed real time calcium imaging assays in transiently transfected HEK293 tsA201 cells. Since M2 mAChRs activate the $\mathrm{G}_{\mathrm{i}}$ protein subfamily, we co-transfected a chimeric $\mathrm{G}_{\mathrm{q} / \mathrm{i}}$-protein in order to couple $\mathrm{M} 2$ receptor activation to the phospholipase $\mathrm{C}$ pathway, thus inducing inositol 1,4,5-trisphosphate $\left(\mathrm{IP}_{3}\right)$ production and subsequent intracellular calcium release from the endoplasmic reticulum. The orthosteric muscarinic superagonist Iperoxo (IPX) $)^{32}$ was also tested in all the experiments as a positive control. Transfected cells gave a sharp response to the application of IPX (30 pM). Since the activity of IPX is not photoswitchable, as expected, the concomitant application of pulses of UV light $(365 \mathrm{~nm})$ or blue light $(460 \mathrm{~nm})$ did not alter calcium responses (Figure 2a). In absence of photoswitchable M2 receptor agonist, light pulses did not induce any effect in the calcium signal (Figure S4.1).

The application of trans-PAI (dark-adapted state) induced cytosolic calcium oscillations indicative of M2 agonism, which were reduced by converting PAI to its $\mathrm{cis}$ form upon illumination with UV light (365 nm) (Figure 2b-c). Oscillations could be restored after back-isomerizing PAI to the trans configuration using blue light $(460 \mathrm{~nm})$. The time course of calcium responses during activation with trans-PAI displayed a diversity of behaviors in individual cells (Figure 2c) including oscillatory waves, transient peaks, and step responses as previously observed with PLC-activating GPCRs. ${ }^{7}$ Quantification of photoresponses $\left(\Delta \mathrm{F} / \mathrm{F}_{0}\right)$ to PAI application and $365 \mathrm{~nm}$ illumination shows a reduction in the calcium signal induced by UV light pulses (Figure 2d). Interestingly, PAI activated M2 $\mathrm{mAChR}$ in the range of picomolar concentrations, similarly to the reference superagonist Iperoxo. ${ }^{32}$ Thus, PAI can effectively activate M2 mAChRs in vitro in its dark-adapted (trans) form and its activity can be reversibly switched off and on by the application of UV and blue light, respectively.

In order to account for the observed photoswitchable activity of PAI in M2 mAChR, we looked for putative differences on the receptor level regarding binding efficacy of cis- and transPAI using molecular docking simulations (see SI for details). In particular, we asked whether the observed differences in activity between the two isomers could be explained by changes of the PAI binding mode in the receptor, as a result of 
the mutual position of the orthosteric and the allosteric groups induced by photoisomerization. The two PAI isomers were docked into the putative allosteric and orthosteric binding sites of the high-resolution X-ray structure of the human M2 mAChR (PDB code: 4MQT). Our docking scores (expressed as predicted binding affinity in $\mathrm{kcal} / \mathrm{mol}$ ) indicated that transPAI can bind to M2 mAChR in a typical dualsteric pose compatible with receptor activation (Figure S5.1a). ${ }^{33}$ In contrast, a flipped orientation is favored in the case of the cis-isomer, with the phthalimide group pointing to the orthosteric binding pocket and the 4,5-dihydroisoxazole moiety positioned in the allosteric binding site (Figure S5.1b). Such a binding mode is likely incompatible with receptor activation and provides a possible explanation for the differences in efficacy observed between the two photo-isomers (Figure S4.2).

The potency and photoswitchable activity displayed by PAI in cardiac M2 receptors in vitro encouraged us to further test it to control cardiac function with light in vivo.
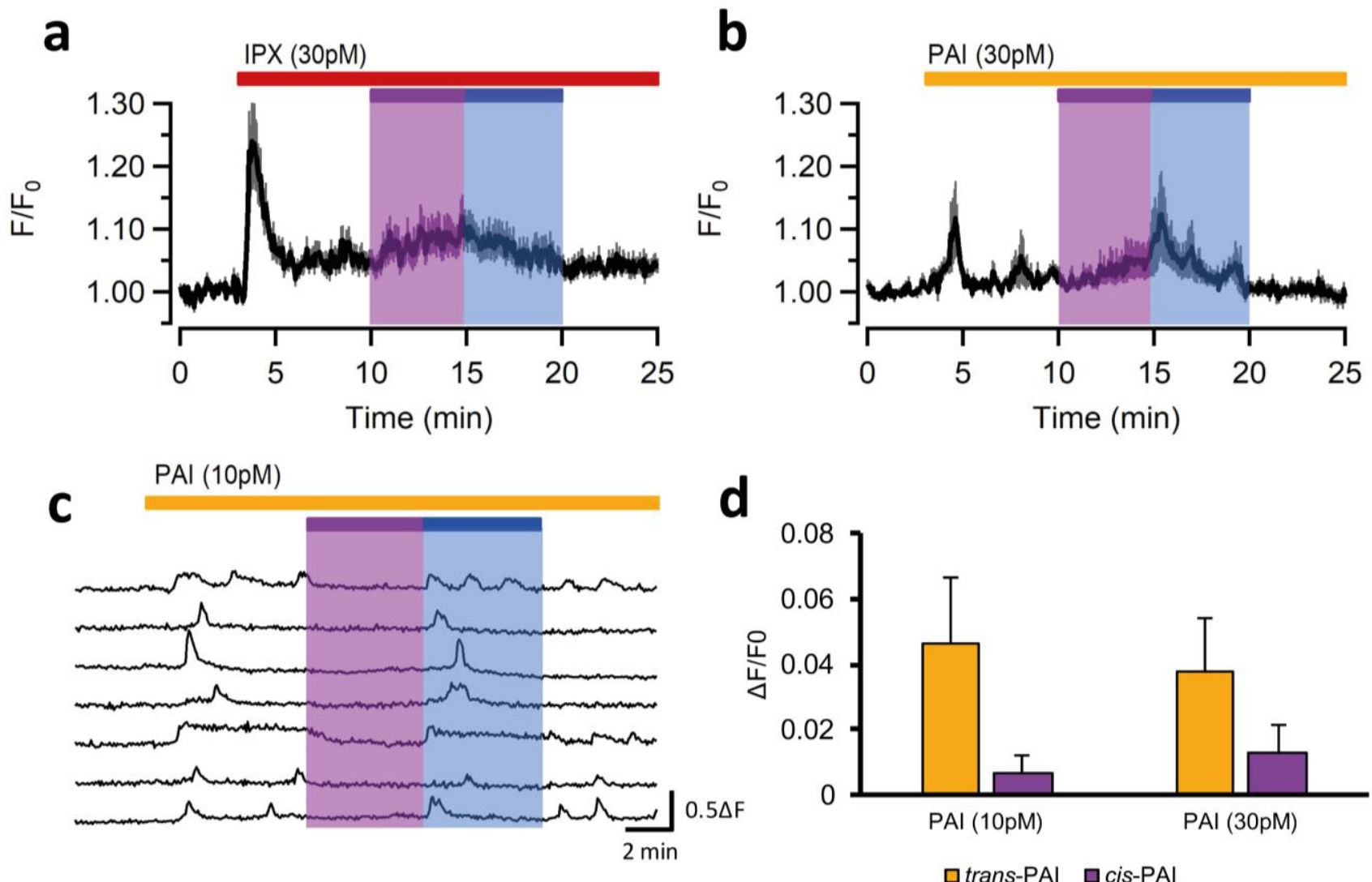

FIGURE 2. PAI reversibly activates M2 mAChRs with light in calcium imaging assays. Real time calcium imaging traces from HEK cells co-expressing M2mAChR and GqTOP loaded with $10 \mu \mathrm{M}$ of the calcium indicator OGB1AM. a) Average trace of cell responses to 30 $\mathrm{pM}$ of non-photoswitchable muscarinic agonist IPX $(\mathrm{n}=130)$. b) Average trace of cell responses to $30 \mathrm{pM}$ of trans-PAI ( $=8)$. c) Single cell calcium responses induced by the direct application of $10 \mathrm{pM}$ of trans-PAI (yellow bar). Purple bars indicate illumination at $365 \mathrm{~nm}$, blue bars indicate illumination at $460 \mathrm{~nm}$. Gray shadow in the recordings represents \pm SEM. d) Quantification of photoresponses to the application of PAI (yellow bar) at $10 \mathrm{pM}(\mathrm{n}=356$ cells from 5 different experiments) and $30 \mathrm{pM}(\mathrm{n}=293$ cells from 6 different experiments); and the recovery after $365 \mathrm{~nm}$ illumination (purple bar). Error bars are \pm SEM.

PAI enables the reversible photopharmacological control of heart rate in Xenopus tropicalis tadpoles.

In order to determine whether PAI enables photocontrolling cardiac function in vivo, we monitored its effects in Xenopus tropicalis tadpoles under different illumination conditions. African clawed frogs constitute an excellent animal model for behavioral, genetic and electrophysiological studies, ${ }^{34,35}$ and a powerful tool for drug discovery and preclinical animal testing. ${ }^{36}$ In addition, they are especially suitable for heart monitoring since tadpoles are transparent until stages $48-50^{37}$ and, in contrast to fish, their cardiovascular system is structurally and physiologically comparable to humans. ${ }^{38,39}$ Video light microscopy has been used to acquire real-time images of the developing beating heart by digitizing the expanding and contracting blood pool in early transparent hearts (Figure 3a). ${ }^{40}$ This has been effective for obtaining angiographic-type estimates of ventricular function and modelling a virtual threechambered heart. ${ }^{38}$

In the absence of PAI, the cardiac rate of tadpoles remained nearly constant at $2.3 \pm 0.1$ beats $\cdot \mathrm{s}^{-1}$ during control illumination with UV light and at $2.10 \pm 0.01$ beats $\cdot \mathrm{s}^{-1}$ in the dark (Figure 3 ). The variability score was $7.97 \pm 0.07$. Upon administration of $10 \mu \mathrm{M}$ PAI in the trans form (dark-adapted state), heart rate decreased dramatically $\left(0.41 \pm 0.02\right.$ beats $\cdot \mathrm{s}^{-1}$ in the 
trace of Figure 3e) leading in some cases to cardiac arrest (Figure 3c). Heart beating recovered progressively upon UV illumination (cis-isomerisation, $1.28 \pm 0.02$ Beats $\cdot \mathrm{s}^{-1}$, Figure $3 \mathrm{f}$ ), and was not altered in the dark due to the slow relaxation lifetime of the cis isomer. Some animals displayed less stable cardiac rate during UV periods compared to controls (variability score $17.4 \pm 0.2$ and $8.30 \pm 0.02$, respectively; Figure S6.3). Subsequent illumination of the animals with visible light, which favours the trans configuration (M2 active), again reduced cardiac rate and eventually interrupted heart beating (variability score $374 \pm 47.7$, Figure S6.3). Cardiac activity was restored by later exposition to UV light, and further UV/visible light cycles confirmed the reversibility of the pharmacological effects of PAI. An example movie of this experiment can be found in the Supporting Information (Movie S1). Overall, these experiments demonstrated that PAI allows reversibly controlling heart rate in Xenopus tropicalis tadpoles under different light conditions.

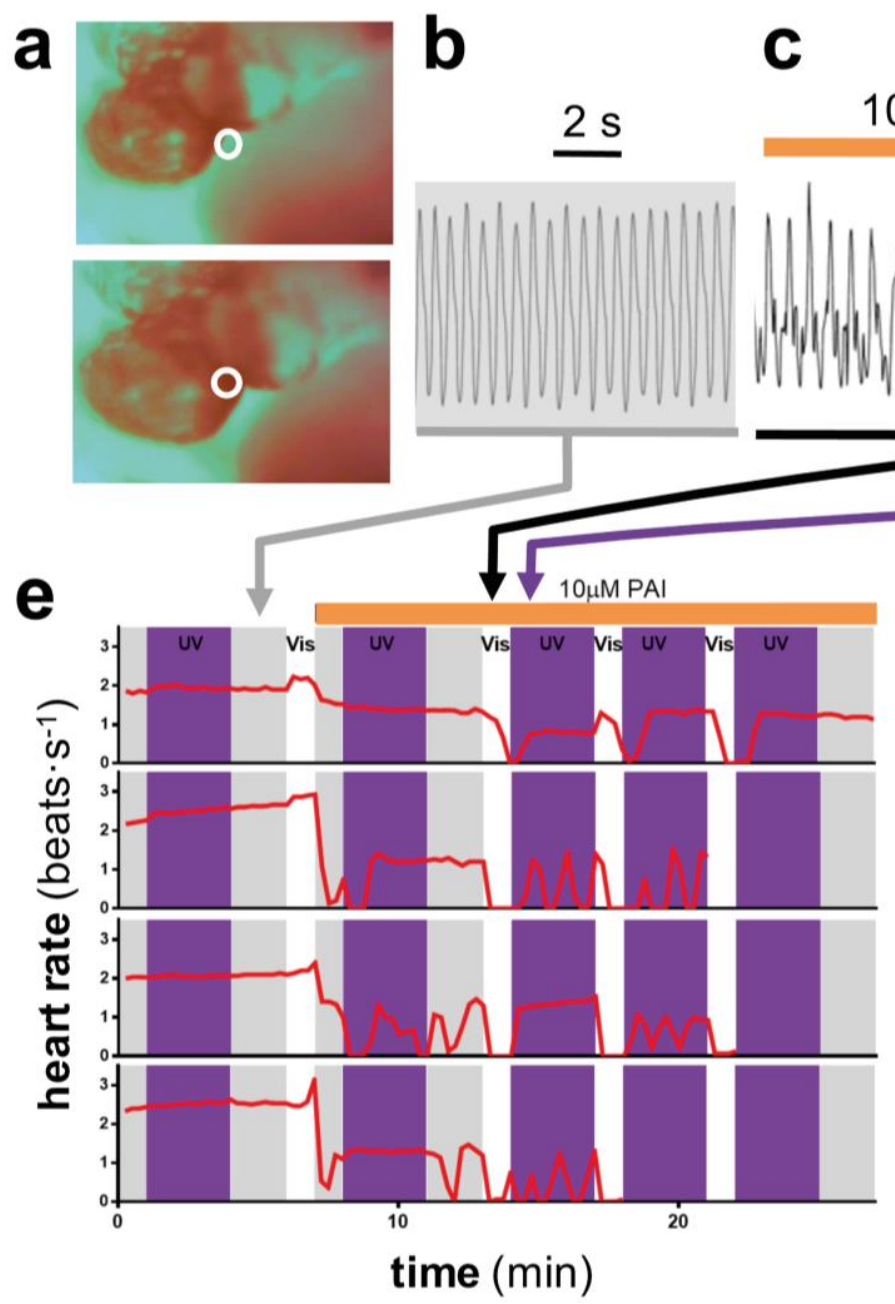

$10 \mu \mathrm{M}$ PAl

d
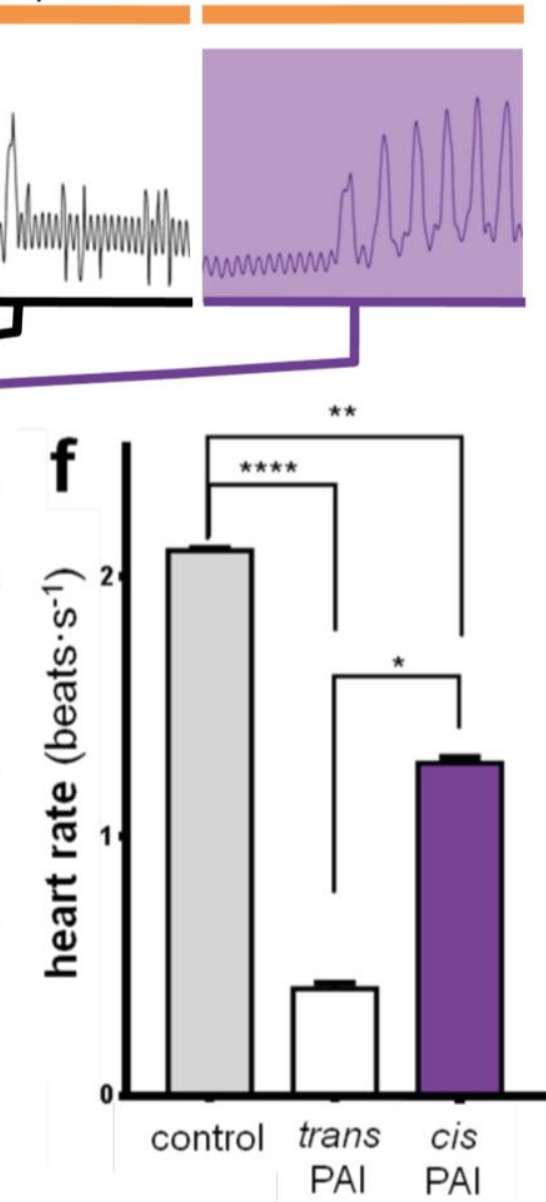

FIGURE 3. Photoregulation of heart rate with PAI in frog tadpoles. a) Two video frames of a paralysed tadpole heart indicating a region of interest (white circle) used to obtain the time course of heart beating movements (average of intensity versus time). b) Normal heartbeat recording obtained in control conditions (dim red light, indicated by a grey shade). Time scale: $2 \mathrm{~s}$. c) Adding $10 \mu \mathrm{M}$ trans-PAI under white light illumination reduces the heartbeat frequency, eventually causing cardiac arrest. d) Under UV illumination (purple shade), trans-PAI is isomerized to cis-PAI and heartbeat is recovered. e) Red traces indicate the heart rate (in beats-s-1, calculated every 15 -s interval) as a function of time in 4 independent experiments with different animals. White, purple, and grey backgrounds indicate illumination with white, UV and dim red light, respectively. Heart rate is not altered by illumination under control conditions (Figure S6.2). Adding $10 \mu \mathrm{M}$ trans-PAI under dim light reduces the heart rate in animals 2, 3 and 4. UV illumination isomerizes PAI to the cis form and the heart rate is partially recovered. Dim red light does not isomerize PAI (Figure S6.1) and heart rate is relatively stable. White light converts PAI to the trans isomer, causing cardiac arrest in all 4 animals. UV light restores heartbeat in all animals, some displaying an unstable rate. Several white/UV light cycles were repeated in some animals, showing similar effects. e) Quantification of heart rate during the last minute of each period (beats $\cdot \mathrm{s}-1, \mathrm{n}=4$ tadpoles) in control conditions, under white light (trans-PAI) and under UV light (cis-PAI). f) Two-way for repeated measures ANOVA was performed with uncorrected Fisher's LSD test, significance values were established with a p-value $=0.05$. Error bars represent standard error of the mean (SEM). The heart rate was significantly higher under UV illumination compared to visible light ( $p$-value $<0.05$ ). Both isomers produced a significant reduction of heart rate in comparison to controls ( $p$-value $<0.001)$. 
Trans-PAI is more effective than cis-PAI at inducing bradycardia and PR lengthening in rats.

We next tested the cardiac parasympathetic activity of PAI in rodents. Intraperitoneal administration of both cis- and transPAI isomers induced progressive bradycardia and PR lengthening in a dose-dependent manner (Figure 4 and Figure S7.1). These effects were accompanied with variable degrees of systemic parasympathetic effects, such as salivation, urination and defecation. At low doses $(\leq 3 \mu \mathrm{M} / \mathrm{kg})$, both isomers yielded a similar small effect, but remarkably differed at intermediate and high doses. At $10 \mu \mathrm{M} / \mathrm{kg}$ PAI and higher doses, the PR interval was significantly more prolonged in the trans-isomer in comparison to the cis-isomer group; at $30 \mu \mathrm{M}$ and higher doses, heart rate was also lower in the trans-isomer compared with the cis-isomer group. Three rats in the trans-group died because of extreme bradycardia after the $100 \mu \mathrm{M} / \mathrm{kg}$ dose. The administration of atropine $(2 \mathrm{mg}$ ) completely reverted bradycardia, PR lengthening and systemic parasympathetic effects in both cis- and trans-isomer groups (Figure S7.1). These results demonstrated an enhanced parasympathetic activity for the trans-isomer of PAI, and confirmed in mammals the previous findings obtained in cells and in Xenopus tropicalis tadpoles.
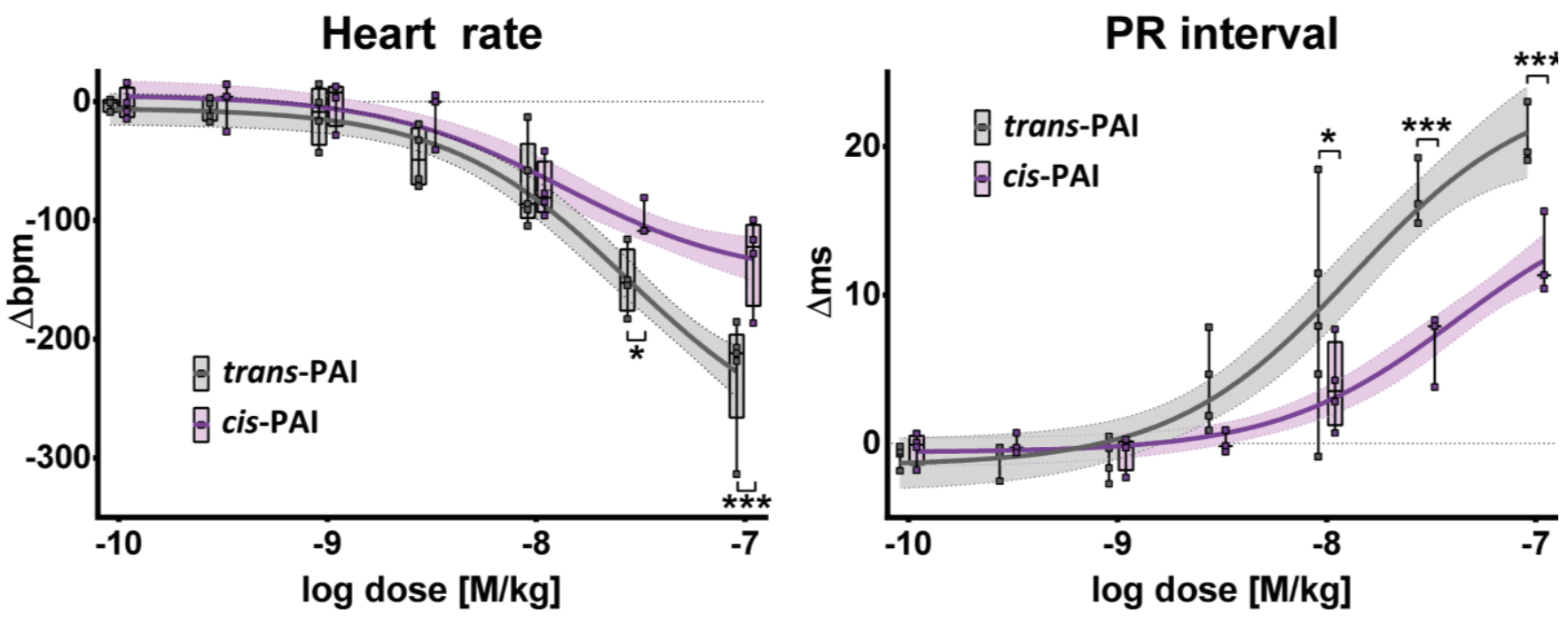

FIGURE 4. In vivo effect of PAI and illumination on the cardiac activity of rats. The activity of dark-relaxed (trans, grey plots) and UV-illuminated PAI (cis, purple plots) administered intraperitoneally in anesthetized rats was tested by means of electrocardiography. The heart rate (left panel) and PR interval (right panel) are plotted as a function of increasing doses of both isomers, which induced progressive bradycardia and PR lengthening in a dose-dependent manner. Significant differences between the dark-relaxed and UV-treated PAI were found in the heart rate and PR interval at the higher doses $(* \mathrm{p}<0.05 ; * * *<0.001$ trans vs cis), in agreement with the higher agonist activity of the trans form observed in vitro and in tadpoles. The effects of PAI were reversible upon administration of the muscarinic antagonist atropine.

\section{DISCUSSION}

In the quest to turn light into physiological effects, and to control a protein target in spatiotemporal designated patterns, a wide variety of light sources for biomedicine are available, ranging from research-grade holographic illumination devices, implanted light-emitting diodes (LEDs) and optic fibers, to clinically approved lamps for phototherapies. However, the key technology for feasible therapeutic approaches is the development of pharmacologically selective, light-regulated drugs for specific indications. Here, we have reached an important milestone in this way by demonstrating for the first time the reversible photoregulation of cardiac function in wildtype animals using a pharmacological approach, without requiring genetic manipulations. In particular, we showed reversible photocontrol of the heart rate in tadpoles simply immersed in the compound. In rodents, the intraperitoneally administered drug induced dose-dependent bradycardia and PR lengthening that were significantly different between the two photoisomers.

These results were achieved with PAI, a photoswitchable agonist of M2 mAChRs that was rationally designed, synthesized and pharmacologically characterized in vitro and in vivo for this purpose. PAI is a potent activator of M2 mAChRs in its trans configuration, and can be effectively switched on and off with white (or blue) and UV light, respectively. Despite the changes introduced in the ligand structure in order to photoregulate its activity, PAI retains high efficacy, similarly to its parent compounds Iperoxo and P-8-Iper. ${ }^{23,32}$

Computational docking studies of PAI in the M2 receptor complemented rational design of the molecule and could be used to further refine its pharmacological and photophysical properties (e.g., red light activation), and to engineer novel light-regulated drugs if the atomic structure of the protein target is available.

PAI constitutes a new lead compound to develop novel cardiac treatments involving the regulation of the parasympathetic system with light via M2 muscarinic receptors. The activity profile of PAI and its light-dependence also offer unique opportunities to study the relationship between orthosteric and dualsteric sites, and to design new light-regulated, subtype selective mAChR agonists or antagonists. 


\section{Modulation of cardiac function with light: optogenetics and photopharmacology.}

Our findings with PAI highlight the potential of lightregulated drugs, complementing those explored by the evolving field of cardiac optogenetics. ${ }^{16,41-43}$ Recent works demonstrated that optogenetics enabled controlling myocardial excitation in vitro in myocardial slices ${ }^{17,44}$ and pluripotent stem cells-derived myocites, ${ }^{45,46}$ and in vivo in mouse and zebrafish models. ${ }^{47,48}$ Moreover, in mechanistic experiments, cardiac optogenetics have also been used to clarify the role of neural cells on the cardioprotection evoked by remote ischemic preconditioning $^{49}$ and on blood pressure control. ${ }^{50}$ However, optogenetic manipulation requires overexpression of opsin proteins, which has shortcomings like low efficacy in transfection, use of viruses, potential integration in the genome, immune reactions against bacterial proteins, limited use to a few model organisms, and alteration of cellular physiology. Although important breakthroughs in gene therapy have been reported in recent clinical trials, ${ }^{51,52}$ translation of successful genetic modification in animal models into human therapies remains an ethical and safety issue.

A pharmacological approach avoids the need to overexpress exogenous proteins or to develop genetically modified organisms, thus expanding the therapeutic opportunities of light regulation. Light regulated drugs have been used to restore vision in animals with retinal degeneration ${ }^{53}$ and to reversible control analgesic effects ${ }^{54}$ and glucose homeostasis. ${ }^{55}$ Here, we report the first successful attempt to modulate cardiac function with light in the absence of any genetic modification.

\section{Potential clinical applications and future developments.}

The present work serves as a proof of concept for drug-based light-controlled cardiac function. The rapid and reversible control of cardiac activity is of particular interest, together with the spatial control of close anatomic structures bearing different electrophysiological functions in the heart. Even if administered systemically, the effects of light-activated drugs could be selectively enhanced in certain areas of the heart (e.g., preventing undesired pro-arrhythmogenic ventricular effects when atria are targeted), or at certain time (on-demand, i.e., active only during atrial fibrillation or bradycardia). Through a similar conceptual approach, experimental works have postulated optogenetics as an alternative for cardiac pacing, ${ }^{18}$ including a potential for cardiac resynchronization, ${ }^{56}$ preventing ventricular arrhythmias by either modulating autonomic tone balance ${ }^{16}$ or inducing conduction block, ${ }^{57}$ and potentially allowing shock-free cardioversion. ${ }^{58}$ Drug-based cardiac photoregulation techniques offer potential advantages compared to electric stimulation of cardiac muscle, which produces inhomogeneous areas of de- and hyperpolarization, causes faradaic reactions that alter $\mathrm{pH}$, and produce toxic gases $\left(\mathrm{H}_{2}, \mathrm{O}_{2}\right.$ or $\mathrm{Cl}_{2}$ ), all of which would be prevented by light-stimulation. Finally, the possibility of including agonists, antagonists, blockers and modulators in the photopharmacological toolbox, and even combining their independent action with different wavelengths of illumination, can provide a great flexibility and a wide array of therapeutic options for cardiologists.

We have shown that PAI yields a potent, controllable negative chronotropic effect in the sinus node. An increasing core of evidence supports that decreased heart rate is central in the control of stable angina, and may increase survival in heart failure patients. ${ }^{59}$ Unfortunately, heart rate control in these pa- tients remains suboptimal. ${ }^{60}$ Drug-based photo-control of heart rate may allow to dynamically and precisely titrate heart rate in patients with such cardiac conditions.

Notwithstanding potential applications, we acknowledge that several limitations should be addressed before clinical applicability becomes feasible. PAI is sensitive to UV light, which has a limited tissue penetration. Drugs photoregulated by red or infrared wavelengths, which are less scattered and penetrate deeper in living tissue may present as more convenient choices. ${ }^{61}$ Alternatively, cardiac patches with complex integrated electronics and electric stimulation, ${ }^{62}$ could be further equipped with optoelectronic devices for photostimulation.

\section{CONCLUSIONS}

Cardiac optogenetics is an emerging method to control the activity of the heart using genetic manipulation and spatiotemporal patterns of illumination. In order to take full advantage of light manipulation in wild type animals, we have developed a light-regulated chemical tool that reversibly activates M2 muscarinic acetylcholine receptors by blue or white light, and deactivates them with UV light. The molecular design builds on a highly potent and selective dualsteric agonist of M2 receptors, and directly enables the reversible manipulation of the parasympathetic nervous system. This compound allows for the first time to regulate cardiac function in a pharmacologically specific and light controlled manner, as demonstrated in cellular assays in vitro and in two wild type animal models (frog tadpoles and rats). Our approach does not require genetic manipulation and offers new opportunities for cardiovascular research and therapeutic treatments.

\section{ASSOCIATED CONTENT}

\section{Supporting Information}

The Supporting Information is available free of charge on the ChemRxiv website. Materials and methods, detailed synthetic procedures, chemical analyses, and any additional data and figures as noted in the text (PDF).

\section{AUTHOR INFORMATION}

\section{Corresponding Author}

* Corresponding author: Prof. Pau Gorostiza, Institute for Bioengineering of Catalonia (IBEC), Barcelona Institute for Science and Technology (BIST), Carrer de Baldiri Reixac 15-21, 08028 Barcelona, Spain. E-mail: pau@icrea.cat.

\section{Author Contributions}

+ Fabio Riefolo and Carlo Matera contributed equally.

All authors have given approval to the final version of the manuscript.

\section{Funding Sources}

This work was supported by funding from AGAUR/Generalitat de Catalunya (CERCA Programme, 2017-SGR-1442 and 2017-SGR1548), FEDER funds, ERANET SynBio MODULIGHTOR, Fundaluce foundation, Ramón Areces foundation, MINECO (FPI fellowship BES-2014-068169 and project CTQ2016-80066R), CATCH-ME (grant agreement $n^{\circ}$ 633196), and from the European Union's Horizon 2020 Framework Programme for Research and Innovation under the Specific Grant Agreement No. 720270 (Human Brain Project SGA1). CM was supported by the Ermenegildo Zegna Founder's Scholarship. LA was supported by the graduate 
program "Receptor Dynamics - Emerging paradigms for novel drugs" funded by the Elite Network of Bavaria.

\section{Notes}

All animal procedures were authorized by the local ethics review boards (IDIBAPS-Hospital Clínic de Barcelona, n.92117, 02/03/2017; Comitè Ėtic d'Experimentació Animal de la Universitat de Barcelona, n.306/18, 25/06/2018).

\section{ACKNOWLEDGMENT}

The authors are grateful to Jean-Philippe Pin for providing the chimeric $\mathrm{Gi} / \mathrm{Gq}$ protein clone and to Núria Camarero for helping during preliminary in vitro experiments. $\mathrm{CM}$ and FR are grateful to Prof. Marco De Amici for helpful discussion and continuous support. Molecular graphics and analyses were performed with the UCSF Chimera package. Chimera is developed by the Resource for Biocomputing, Visualization, and Informatics at the University of California, San Francisco (supported by NIGMS P41-GM103311). Mass spectrometry was performed at the IRB Barcelona Mass Spectrometry Core Facility, which actively participates in the BMBS European COST Action BM 1403 and is a member of Proteored, PRB2-ISCIII, supported by grant PRB2 (IPT13/0001 - ISCIII-SGEFI / FEDER).

\section{REFERENCES}

(1) Hanahan, D.; Weinberg, R. A. Hallmarks of Cancer: The next Generation. Cell 2011, 144 (5), 646-674.

(2) Edwards, I. R.; Aronson, J. K. Adverse Drug Reactions: Definitions, Diagnosis, and Management. Lancet (London, England) 2000, 356 (9237), 1255-1259.

(3) Lerch, M. M.; Hansen, M. J.; van Dam, G. M.; Szymanski, W.; Feringa, B. L. Emerging Targets in Photopharmacology. Angew. Chem. Int. Ed. Engl. 2016, 55 (37), 10978-10999.

(4) Izquierdo-Serra, M.; Trauner, D.; Llobet, A.; Gorostiza, P. Optica Modulation of Neurotransmission Using Calcium Photocurrents through the Ion Channel LiGluR. Front. Mol. Neurosci. 2013, 6, 3.

(5) Nevola, L.; Martín-Quirós, A.; Eckelt, K.; Camarero, N.; Tosi, S.; Llobet, A.; Giralt, E.; Gorostiza, P. Light-Regulated Stapled Peptides to Inhibit Protein-Protein Interactions Involved in Clathrin-Mediated Endocytosis. Angew. Chemie Int. Ed. 2013, 52 (30), 7704-7708

(6) Izquierdo-Serra, M.; Gascón-Moya, M.; Hirtz, J. J.; Pittolo, S.; Poskanzer, K. E.; Ferrer, E.; Alibés, R.; Busqué, F.; Yuste, R.; Hernando, J.; et al. Two-Photon Neuronal and Astrocytic Stimulation with Azobenzene-Based Photoswitches. J. Am. Chem. Soc. 2014, 136 (24), 8693-8701.

(7) Pittolo, S.; Gómez-Santacana, X.; Eckelt, K.; Rovira, X.; Dalton, J.; Goudet, C.; Pin, J.-P.; Llobet, A.; Giraldo, J.; Llebaria, A.; et al. An Allosteric Modulator to Control Endogenous G Protein-Coupled Receptors with Light. Nat. Chem. Biol. 2014, 10 (10), 813-815.

(8) Izquierdo-Serra, M.; Bautista-Barrufet, A.; Trapero, A.; GarridoCharles, A.; Díaz-Tahoces, A.; Camarero, N.; Pittolo, S.; Valbuena, S.; Pérez-Jiménez, A.; Gay, M.; et al. Optical Control of Endogenous Receptors and Cellular Excitability Using Targeted Covalent Photoswitches. Nat. Commun. 2016, 7, 12221.

(9) Velema, W. A.; Szymanski, W.; Feringa, B. L. Photopharmacology: Beyond Proof of Principle. J. Am. Chem. Soc. 2014, 136 (6), 2178-2191.

(10) Boyle, P. M.; Karathanos, T. V; Trayanova, N. A. "Beauty Is a Light in the Heart": The Transformative Potential of Optogenetics for Clinical Applications in Cardiovascular Medicine. Trends Cardiovasc. Med. 2015, 25 (2), 73-81.

(11) Hamaoka, T.; McCully, K. K.; Quaresima, V.; Yamamoto, K.; Chance, B. Near-Infrared Spectroscopy/imaging for Monitoring Muscle Oxygenation and Oxidative Metabolism in Healthy and Diseased Humans. J. Biomed. Opt. 2007, 12 (6), 62105.

(12) Taub, A. F. Photodynamic Therapy in Dermatology: History and Horizons. J. Drugs Dermatol. 3 (1 Suppl), S8-25.

(13) Kale, R. P.; Kouzani, A. Z.; Walder, K.; Berk, M.; Tye, S. J. Evolution of Optogenetic Microdevices. Neurophotonics 2015, 2 (3), 31206.

(14) Fabritz, L.; Guasch, E.; Antoniades, C.; Bardinet, I.; Benninger, G.;
Betts, T. R.; Brand, E.; Breithardt, G.; Bucklar-Suchankova, G.; Camm, A. J.; et al. Expert Consensus Document: Defining the Major Health Modifiers Causing Atrial Fibrillation: A Roadmap to Underpin Personalized Prevention and Treatment. Nat. Rev. Cardiol. 2016, 13 (4), 230-237.

(15) Pianca, N.; Zaglia, T.; Mongillo, M. Will Cardiac Optogenetics Find the Way through the Obscure Angles of Heart Physiology? Biochem. Biophys. Res. Commun. 2017, 482 (4), 515-523.

(16) Yu, L.; Zhou, L.; Cao, G.; Po, S. S.; Huang, B.; Zhou, X.; Wang, M.; Yuan, S.; Wang, Z.; Wang, S.; et al. Optogenetic Modulation of Cardiac Sympathetic Nerve Activity to Prevent Ventricular Arrhythmias. J. Am. Coll. Cardiol. 2017, 70 (22), 2778-2790.

(17) Bingen, B. O.; Engels, M. C.; Schalij, M. J.; Jangsangthong, W.; Neshati, Z.; Feola, I.; Ypey, D. L.; Askar, S. F. A.; Panfilov, A. V.; Pijnappels, D. A.; et al. Light-Induced Termination of Spiral Wave Arrhythmias by Optogenetic Engineering of Atrial Cardiomyocytes Cardiovasc. Res. 2014, 104 (1), 194-205.

(18) Bruegmann, T.; Boyle, P. M.; Vogt, C. C.; Karathanos, T. V; Arevalo, H. J.; Fleischmann, B. K.; Trayanova, N. A.; Sasse, P. Optogenetic Defibrillation Terminates Ventricular Arrhythmia in Mouse Hearts and Human Simulations. J. Clin. Invest. 2016, 126 (10), 3894-3904

(19) Brodde, O. E.; Michel, M. C. Adrenergic and Muscarinic Receptors in the Human Heart. Pharmacol. Rev. 1999, 51 (4), 651-690.

(20) Brodde, O.-E.; Bruck, H.; Leineweber, K.; Seyfarth, T. Presence, Distribution and Physiological Function of Adrenergic and Muscarinic Receptor Subtypes in the Human Heart. Basic Res. Cardiol. 2001, 96 (6), 528-538.

(21) Dhein, S.; van Koppen, C. J.; Brodde, O. E. Muscarinic Receptors in the Mammalian Heart. Pharmacol. Res. 2001, 44 (3), 161-182.

(22) Bock, A.; Merten, N.; Schrage, R.; Dallanoce, C.; Bätz, J.; Klöckner, J.; Schmitz, J.; Matera, C.; Simon, K.; Kebig, A.; et al. The Allosteric Vestibule of a Seven Transmembrane Helical Receptor Controls G-Protein Coupling. Nat. Commun. 2012, 3 , 1044

(23) Matera, C.; Flammini, L.; Quadri, M.; Vivo, V.; Ballabeni, V.; Holzgrabe, U.; Mohr, K.; De Amici, M.; Barocelli, E.; Bertoni, S. et al. Bis(ammonio)alkane-Type Agonists of Muscarinic Acetylcholine Receptors: Synthesis, in Vitro Functiona Characterization, and in Vivo Evaluation of Their Analgesic Activity. Eur. J. Med. Chem. 2014, 75, 222-232.

(24) Caulfield, M. P.; Birdsall, N. J. International Union of Pharmacology. XVII. Classification of Muscarinic Acetylcholine Receptors. Pharmacol. Rev. 1998, 50 (2), 279-290.

(25) De Amici, M.; Dallanoce, C.; Holzgrabe, U.; Tränkle, C.; Mohr, K. Allosteric Ligands for $G$ Protein-Coupled Receptors: A Novel Strategy with Attractive Therapeutic Opportunities. Med. Res. Rev. 2009, 30 (3), n/a-n/a.

(26) Mohr, K.; Tränkle, C.; Kostenis, E.; Barocelli, E.; De Amici, M.; Holzgrabe, U. Rational Design of Dualsteric GPCR Ligands: Quests and Promise. Br. J. Pharmacol. 2010, 159 (5), 997-1008.

(27) Disingrini, T.; Muth, M.; Dallanoce, C.; Barocelli, E.; Bertoni, S.; Kellershohn, K.; Mohr, K.; De Amici, M.; Holzgrabe, U. Design, Synthesis, and Action of Oxotremorine-Related Hybrid-Type Allosteric Modulators of Muscarinic Acetylcholine Receptors. J. Med. Chem. 2006, 49 (1), 366-372.

(28) Antony, J.; Kellershohn, K.; Mohr-Andrä, M.; Kebig, A.; Prilla, S.; Muth, M.; Heller, E.; Disingrini, T.; Dallanoce, C.; Bertoni, S.; et al. Dualsteric GPCR Targeting: A Novel Route to Binding and Signaling Pathway Selectivity. FASEB J. 2009, 23 (2), 442-450.

(29) Matera, C.; Tata, A. M. Pharmacological Approaches to Targeting Muscarinic Acetylcholine Receptors. Recent Pat. CNS Drug Discov. 2014, 9 (2), 85-100.

(30) De Min, A.; Matera, C.; Bock, A.; Holze, J.; Kloeckner, J.; Muth M.; Traenkle, C.; De Amici, M.; Kenakin, T.; Holzgrabe, U.; et al. A New Molecular Mechanism To Engineer Protean Agonism at a G Protein-Coupled Receptor. Mol. Pharmacol. 2017, 91 (4), 348-356.

(31) Agnetta, L.; Kauk, M.; Canizal, M. C. A.; Messerer, R.; Holzgrabe, U.; Hoffmann, C.; Decker, M. A Photoswitchable Dualsteric Ligand Controlling Receptor Efficacy. Angew. Chem. Int. Ed. Engl. 2017, 56 (25), 7282-7287.

(32) Schrage, R.; Seemann, W. K.; Klöckner, J.; Dallanoce, C.; Racké K.; Kostenis, E.; De Amici, M.; Holzgrabe, U.; Mohr, K. Agonists with Supraphysiological Efficacy at the Muscarinic M2 ACh 
Receptor. Br. J. Pharmacol. 2013, 169 (2), 357-370.

(33) Bock, A.; Bermudez, M.; Krebs, F.; Matera, C.; Chirinda, B.; Sydow, D.; Dallanoce, C.; Holzgrabe, U.; De Amici, M.; Lohse, M. J.; et al. Ligand Binding Ensembles Determine Graded Agonist Efficacies at a G Protein-Coupled Receptor. J. Biol. Chem. 2016, 291 (31), 16375-16389.

(34) Grainger, R. M. Xenopus Protocols. 2012, 917, 1-11.

(35) Burggren, W. W.; Warburton, S. Amphibians as Animal Models for Laboratory Research in Physiology. ILAR J. 2007, 48 (3), 260-269.

(36) Schmitt, S. M.; Gull, M.; Brändli, A. W. Engineering Xenopus Embryos for Phenotypic Drug Discovery Screening. Adv. Drug Deliv. Rev. 2014, 69-70, 225-246.

(37) Nieuwkoop P., F. J. Normal Table of Xenopus Laevis (Daudin): A Systematical \& Chronological Survey of the Development from the Fertilized Egg till the End of Metamorphosis; 1994.

(38) Boppart, S. A.; Tearney, G. J.; Bouma, B. E.; Southern, J. F.; Brezinski, M. E.; Fujimoto, J. G. Noninvasive Assessment of the Developing Xenopus Cardiovascular System Using Optical Coherence Tomography. Proc. Natl .Acad. Sci. USA 1997, 94 (9), 4256-4261.

(39) Bartlett, H. L.; , Scholz, T. D.; Lamb, F. S.; And; Weeks, D. L. Characterization of Embryonic Cardiac Pacemaker and Atrioventricular Conduction Physiology in Xenopus Laevis Using Noninvasive Imaging. J. Am. Coll. Cardiol. 2004, 37 (2), A379A452.

(40) Eckelt, K.; Masanas, H.; Llobet, A.; Gorostiza, P. Automated HighThroughput Measurement of Body Movements and Cardiac Activity of Xenopus Tropicalis Tadpoles. J. Biol. Methods 2014, 1 (2), 9

(41) Cochet, H.; Dubois, R.; Yamashita, S.; Al Jefairi, N.; Berte, B.; Sellal, J.-M.; Hooks, D.; Frontera, A.; Amraoui, S.; Zemoura, A.; et al. Relationship Between Fibrosis Detected on Late GadoliniumEnhanced Cardiac Magnetic Resonance and Re-Entrant Activity Assessed With Electrocardiographic Imaging in Human Persistent Atrial Fibrillation. JACC. Clin. Electrophysiol. 2018, 4 (1), 17-29.

(42) Gepstein, L.; Gruber, A. Optogenetic Neuromodulation of the Heart. J. Am. Coll. Cardiol. 2017, 70 (22), 2791-2794.

(43) Schneider-Warme, F.; Ravens, U. Using Light to Fight Atrial Fibrillation. Cardiovasc. Res. 2018, 114 (5), 635-637.

(44) Burton, R. A. B.; Klimas, A.; Ambrosi, C. M.; Tomek, J.; Corbett, A.; Entcheva, E.; Bub, G. Optical Control of Excitation Waves in Cardiac Tissue. Nat. Photonics 2015, 9 (12), 813-816.

(45) Abilez, O. J. Cardiac Optogenetics. Conf. Proc. ... Annu. Int. Conf. IEEE Eng. Med. Biol. Soc. IEEE Eng. Med. Biol. Soc. Annu. Conf. 2012, 2012, 1386-1389.

(46) Zhuge, Y.; Patlolla, B.; Ramakrishnan, C.; Beygui, R. E.; Zarins, C. K.; Deisseroth, K.; Kuhl, E.; Abilez, O. J. Human Pluripotent Stem Cell Tools for Cardiac Optogenetics. Conf. Proc. ... Annu. Int. Conf. IEEE Eng. Med. Biol. Soc. IEEE Eng. Med. Biol. Soc. Annu. Conf. 2014, 2014, 6171-6174.

(47) Arrenberg, A. B.; Stainier, D. Y. R.; Baier, H.; Huisken, J. Optogenetic Control of Cardiac Function. Science 2010, 330 (6006), 971-974.

(48) Bruegmann, T.; Malan, D.; Hesse, M.; Beiert, T.; Fuegemann, C. J.; Fleischmann, B. K.; Sasse, P. Optogenetic Control of Heart Muscle in Vitro and in Vivo. Nat. Methods 2010, 7 (11), 897-900.

(49) Mastitskaya, S.; Marina, N.; Gourine, A.; Gilbey, M. P.; Spyer, K. M.; Teschemacher, A. G.; Kasparov, S.; Trapp, S.; Ackland, G. L.; Gourine, A. V. Cardioprotection Evoked by Remote Ischaemic
Preconditioning Is Critically Dependent on the Activity of Vagal Pre-Ganglionic Neurones. Cardiovasc. Res. 2012, 95 (4), 487-494.

(50) Tsubota, T.; Ohashi, Y.; Tamura, K.; Miyashita, Y. Optogenetic Inhibition of Purkinje Cell Activity Reveals Cerebellar Control of Blood Pressure during Postural Alterations in Anesthetized Rats. Neuroscience 2012, 210, 137-144.

(51) Busskamp, V.; Picaud, S.; Sahel, J. A.; Roska, B. Optogenetic Therapy for Retinitis Pigmentosa. Gene Ther. 2012, 19 (2), 169 175.

(52) Henriksen, B. S.; Marc, R. E.; Bernstein, P. S. Optogenetics for Retinal Disorders. J. Ophthalmic Vis. Res. 9 (3), 374-382.

(53) Gaub, B. M.; Berry, M. H.; Holt, A. E.; Reiner, A.; Kienzler, M. A.; Dolgova, N.; Nikonov, S.; Aguirre, G. D.; Beltran, W. A.; Flannery, J. G.; et al. Restoration of Visual Function by Expression of a Light-Gated Mammalian Ion Channel in Retinal Ganglion Cells or ON-Bipolar Cells. Proc. Natl. Acad. Sci. 2014, 111 (51), E5574E5583.

(54) Gómez-Santacana, X.; Pittolo, S.; Rovira, X.; Lopez, M.; Zussy, C.; Dalton, J. A. R.; Faucherre, A.; Jopling, C.; Pin, J.-P.; Ciruela, F.; et al. Illuminating Phenylazopyridines To Photoswitch Metabotropic Glutamate Receptors: From the Flask to the Animals. ACS Cent Sci. 2017, 3 (1), 81-91.

(55) Mehta, Z. B.; Johnston, N. R.; Nguyen-Tu, M.-S.; Broichhagen, J.; Schultz, P.; Larner, D. P.; Leclerc, I.; Trauner, D.; Rutter, G. A. Hodson, D. J. Remote Control of Glucose Homeostasis in Vivo Using Photopharmacology. Sci. Rep. 2017, 7 (1), 291.

(56) Nussinovitch, U.; Gepstein, L. Optogenetics for in Vivo Cardiac Pacing and Resynchronization Therapies. Nat. Biotechnol. 2015, 33 (7), 750-754

(57) Watanabe, M.; Feola, I.; Majumder, R.; Jangsangthong, W.; Teplenin, A. S.; Ypey, D. L.; Schalij, M. J.; Zeppenfeld, K.; de Vries, A. A. F.; Pijnappels, D. A. Optogenetic Manipulation of Anatomical Re-Entry by Light-Guided Generation of a Reversible Local Conduction Block. Cardiovasc. Res. 2017, 113 (3), 354-366.

(58) Nyns, E. C. A.; Kip, A.; Bart, C. I.; Plomp, J. J.; Zeppenfeld, K.; Schalij, M. J.; de Vries, A. A. F.; Pijnappels, D. A. Optogenetic Termination of Ventricular Arrhythmias in the Whole Heart: Towards Biological Cardiac Rhythm Management. Eur. Heart J. 2017, 38 (27), 2132-2136.

(59) Swedberg, K.; Komajda, M.; Böhm, M.; Borer, J. S.; Ford, I.; Dubost-Brama, A.; Lerebours, G.; Tavazzi, L.; SHIFT Investigators. Ivabradine and Outcomes in Chronic Heart Failure (SHIFT): A Randomised Placebo-Controlled Study. Lancet 2010, 376 (9744), 875-885

(60) Daly, C. A.; Clemens, F.; Sendon, J. L. L.; Tavazzi, L.; Boersma, E.; Danchin, N.; Delahaye, F.; Gitt, A.; Julian, D.; Mulcahy, D.; et al. Inadequate Control of Heart Rate in Patients with Stable Angina: Results from the European Heart Survey. Postgrad. Med. J. 2010, 86 (1014), 212-217.

(61) Dong, M.; Babalhavaeji, A.; Samanta, S.; Beharry, A. A.; Woolley, G. A. Red-Shifting Azobenzene Photoswitches for in Vivo Use. Acc. Chem. Res. 2015, 48 (10), 2662-2670.

(62) Feiner, R.; Engel, L.; Fleischer, S.; Malki, M.; Gal, I.; Shapira, A.; Shacham-Diamand, Y.; Dvir, T. Engineered Hybrid Cardiac Patches with Multifunctional Electronics for Online Monitoring and Regulation of Tissue Function. Nat. Mater. 2016, 15 (6), 679-685. 
Artwork for Table of Contents

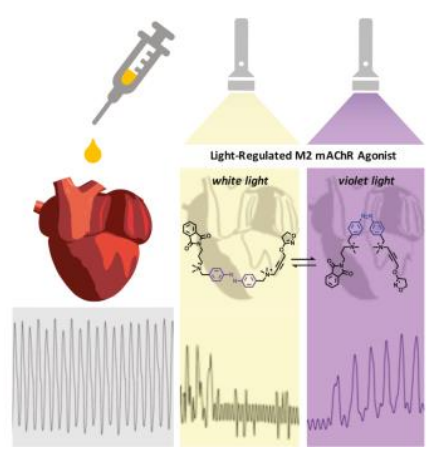


Control of cardiac function in vivo with a light-regulated d... (679.51 KiB) view on ChemRxiv • download file 


\section{Supporting Information}

\section{Control of cardiac function in vivo with a light-regulated drug}

Fabio Riefoloł, Carlo Materał, Aida Garrido-Charles, Alexandre Gomila, Luca Agnetta, Enrique Claro, Roser Masgrau, Ulrike Holzgrabe, Montserrat Batlle, Michael Decker, Eduard Guasch, and Pau Gorostiza*

\section{Contents}

1. Chemical synthesis

2. Photochemical characterization

3. NMR spectroscopy and mass spectrometry

4. In vitro calcium imaging experiments

5. Molecular docking simulations

6. In vivo experiments in $X$. tropicalis tadpoles

7. In vivo experiments in rats

8. Additional references 


\section{Chemical synthesis}

\subsection{Materials and methods}

All reagents and solvents were purchased from Sigma-Aldrich and Serviquimia and were used without any further purification. All reactions were performed under inert atmosphere of argon or nitrogen, unless differently stated. TLC analyses were performed on commercial silica gel $60 \mathrm{~F}_{254}$ aluminium foils (Merck); spots were further evidenced by spraying with a dilute alkaline potassium permanganate solution or a phosphomolybdic acid solution $5 \%$ in ethanol and, for tertiary amines and quaternary ammonium compounds, with the Dragendorff reagent. Flash chromatography was performed on PanReac AppliChem silica gel 60 (40-63 microns) as stationary phase; mobile phases are specified for each compound. UV/Vis spectra and experiments were recorded with a Shimadzu UV-1800 UV-VIS Spectrophotometer with standard quartz cuvettes (10 $\mathrm{mm}$ light path).

${ }^{1} \mathrm{H}-\mathrm{NMR},{ }^{13} \mathrm{C}-\mathrm{NMR}, \mathrm{COSY}$ and $\mathrm{HSQC}$ spectra were registered with a Varian Mercury $400 \mathrm{MHz}$ instrument (400 $\mathrm{MHz}$ for ${ }^{1} \mathrm{H}-\mathrm{NMR}$ and $101 \mathrm{MHz}$ for ${ }^{13} \mathrm{C}-\mathrm{NMR}$ ) in DMSO- $d_{6}, \mathrm{CDCl}_{3}, \mathrm{CD}_{3} \mathrm{OD}$. Residual signals of the deuterated solvents were used as an internal standard (DMSO-d6: ${ }^{1} \mathrm{H} 2.50$ ppm, ${ }^{13} \mathrm{C} 39.52$ ppm; $\mathrm{CDCl}_{3}:{ }^{1} \mathrm{H} 7.26 p p m,{ }^{13} \mathrm{C}$ $77.16 \mathrm{ppm} ; \mathrm{CD}_{3} \mathrm{OD}:{ }^{1} \mathrm{H} 3.31 \mathrm{ppm},{ }^{13} \mathrm{C} 49.00 \mathrm{ppm}$ ). Chemical shifts $(\delta)$ are expressed as parts-per-million (ppm) and coupling constants $(J)$ as hertz $(\mathrm{Hz})$.

HPLC analyses and purification were performed with a Waters Alliance e2695 Separations Module, equipped with a Waters 2998 UV/Vis Photodiode Array Detector and a Waters ACQUITY QDa Mass Detector for detecting the analytes and a XSelect CSH C18 OBD Prep Column $(130 \AA, 5 \mu \mathrm{m}, 10 \mathrm{~mm} \mathrm{X} 150 \mathrm{~mm}, 1 / \mathrm{pkg}$, Waters). Water with $0.1 \%$ formic acid $(\mathrm{v} / \mathrm{v})$ and acetonitrile with $0.1 \%$ formic acid $(\mathrm{v} / \mathrm{v})$ were used as mobile phases (named $A$ and $B$, respectively) with the following gradient: concentration phase $B: 5 \rightarrow 25 \%$ from 0 to $4 \mathrm{~min} ; 25 \%$ from 4 to $7 \mathrm{~min} ; 25 \rightarrow 100 \%$ from 7 to $9 \mathrm{~min} ; 100 \rightarrow 5 \%$ from 9 to $11 \mathrm{~min} ; 5 \%$ from 11 to $12 \mathrm{~min}$. The flow rate was of $3 \mathrm{~mL} \mathrm{~min}$. The purity of PAl compound was found to be $\geq 95 \%$.

High resolution mass spectroscopy measurements (ionization: NanoESI, positive ionization) were performed at the mass spectrometry core facility of the IRB (Barcelona, Spain) with a LTQ-FT Ultra (Thermo Scientific) for direct infusion (Automated Nanoelectrospray) of the sample. The NanoMate (AdvionBioSciences, Ithaca, NY, USA) aspirated the samples from a 384-well plate (protein Lobind) with disposable, conductive pipette tips, and infused the samples through the nanoESI Chip (which consists of 400 nozzles in a $20 \times 20$ array) towards the mass spectrometer. Spray voltage was $1.70 \mathrm{kV}$ and delivery pressure was $0.50 \mathrm{psi}$. Data are reported as mass-to-charge ratio $(\mathrm{m} / \mathrm{z})$ of the corresponding positively charged molecular ions.

\subsection{Abbreviations}

Solvents: AcOEt: ethyl acetate; $\mathrm{DCM}$ : dichloromethane; $\mathrm{MeCN}$ : acetonitrile; $\mathrm{MeOH}$ : methanol; EtOH: ethanol; THF: tetrahydrofuran; $\mathrm{Et}_{2} \mathrm{O}$ : diethyl ether; $\mathrm{iPr}_{2} \mathrm{O}$ : diisopropyl ether; $\mathrm{DMSO}$ : dimethylsulfoxide.

Analytical characterizations: NMR: $d$ : doublet; dd: double doublet; ddd: double double doublet; dt: double triplet; m: multiplet; q: quartet; quin: quintet; s: singlet; $\mathrm{t}$ : triplet; m.p.: melting point; $R_{\mathrm{f}}$ : retention factor; r.t.: room temperature; RT: retention time. 


\subsection{Synthetic procedures}

Iperoxo was prepared following procedures reported in the literature. ${ }^{1,2}$

PAI has been prepared by combining three different building blocks: (a) a photo-isomerizable spacer (5), (b) an allosteric W84-like fragment (8), and (c) an orthosteric Iperoxo-like moiety (Scheme S1).

For the preparation of the photoswitchable spacer (5) we investigated two different synthetic approaches (Routes A and B). Route A gave a higher overall yield compared to Route B ( $49 \%$ vs $24 \%$ ), although we finally preferred Route $B$ because it resulted more elegant, faster, and easier to implement, especially in terms of workup procedures.

Route A: 4,4'-(diazene-1,2-diyl)dibenzoic acid 2 was obtained via an azo-coupling reaction of commercial 4nitrobenzoic acid in the presence of $D-(+)$-glucose and sodium hydroxide ${ }^{3}$ and subsequently esterified with ethanol under acidic catalysis to afford diethyl 4,4'-(diazene-1,2-diyl)dibenzoate 3. Compound $\mathbf{3}$ was then reduced with lithium aluminum hydride to give the corresponding hydroxymethyl derivative $\mathbf{4}$ which was finally brominated in the presence of $\mathrm{N}$-bromosuccinimide and triphenylphosphine to yield compound $\mathbf{5}$.

Route B: 4,4'-dimethylazobenzene $\mathbf{7}$ has been prepared as reported in literature by Velema et al. ${ }^{4}$ and then converted into 4,4'-bis(bromomethyl)azobenzene 5 via a light-induced benzylic bromination in the presence of $\mathrm{N}$-bromosuccinimide. ${ }^{5}$

Intermediates $\mathbf{8}$ and $\mathbf{1 0}$ were prepared by following the synthetic procedures reported in literature. ${ }^{1,2,6}$ The photoswitchable spacer (5) was then attached to the allosteric (8) and the orthosteric (10) fragments through two subsequent reactions of quaternization (Menshutkin) to afford the desired final compound (PAI, 1).
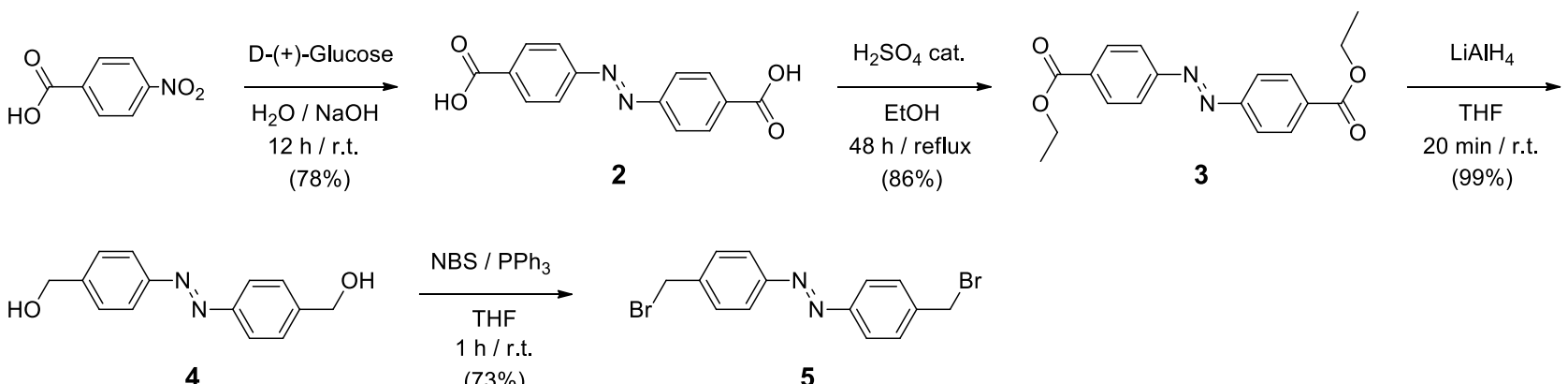

$(73 \%)$

5
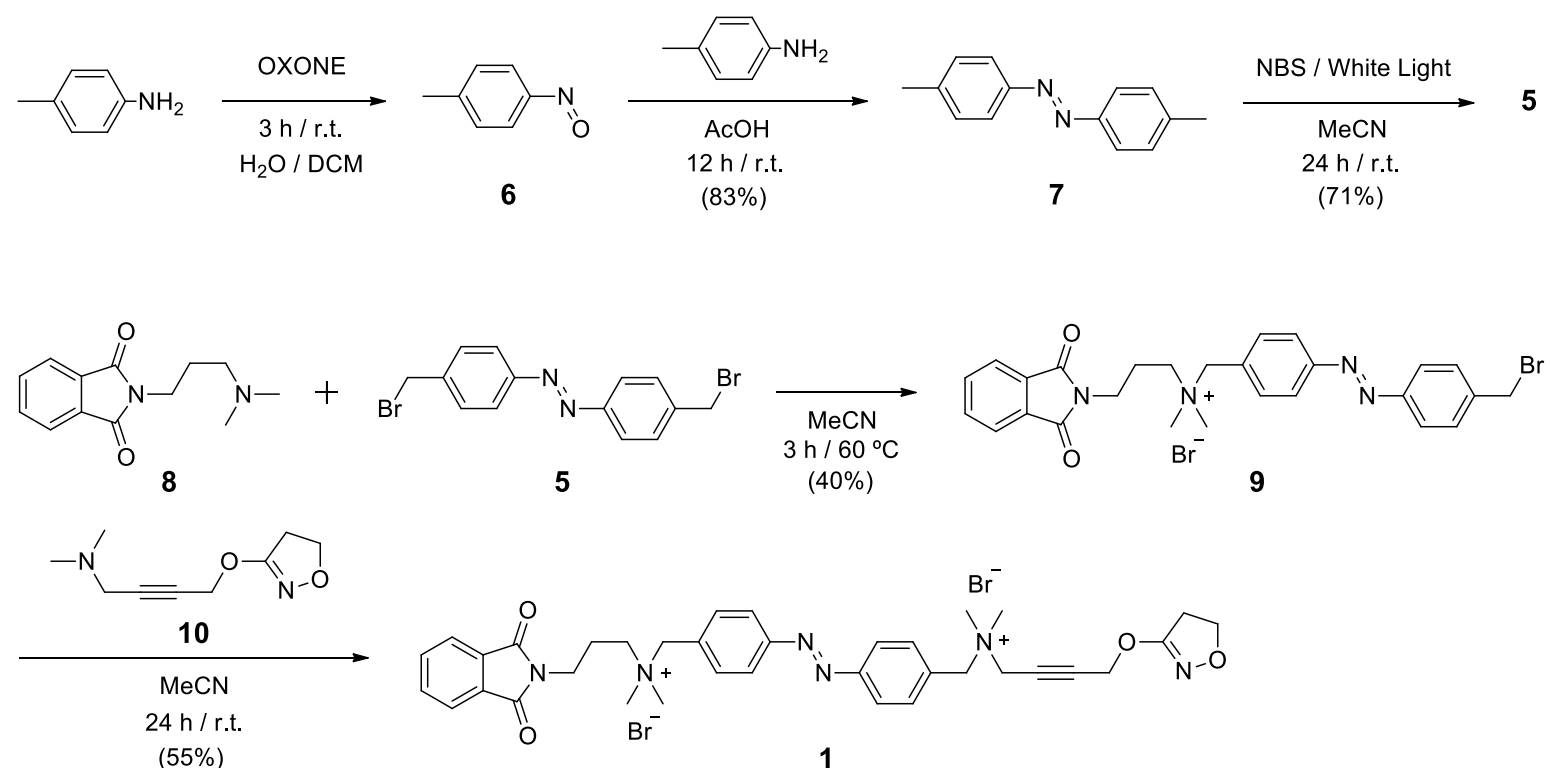

Scheme S1. Chemical synthesis of PAI. 


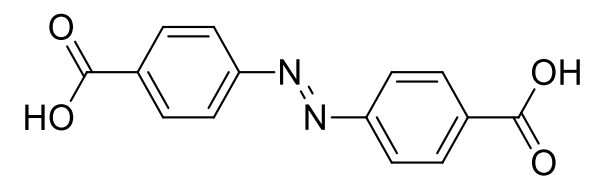

An aqueous solution of glucose ( $30 \mathrm{~g}$ in $50 \mathrm{~mL}$ of water) at $50{ }^{\circ} \mathrm{C}$ was added dropwise to a solution of 4nitrobenzoic acid $(5.00 \mathrm{~g}, 30.00 \mathrm{mmol})$ and sodium hydroxide $(17.00 \mathrm{~g}, 425.03 \mathrm{mmol})$ in $\mathrm{H}_{2} \mathrm{O}(80 \mathrm{~mL})$ at $50{ }^{\circ} \mathrm{C}$ and the corresponding mixture was stirred at room temperature for 12 hours. The obtained brown precipitate was recovered by filtration and washed with brine, then re-dissolved in water $(500 \mathrm{~mL})$ and carefully acidified with acetic acid $(20 \mathrm{~mL})$ to afford a pink precipitate. The pink solid was then collected on a paper filter, washed with water and dried under vacuum to yield $\mathbf{2}$ ( $3.15 \mathrm{~g}, 78 \%$ yield).

m.p.: $117^{\circ} \mathrm{C}$

${ }^{1} \mathrm{H}$ NMR (400 MHz, DMSO- $\left.d_{6}\right) \delta 8.17(\mathrm{~d}, J=8.5 \mathrm{~Hz}, 1 \mathrm{H}), 8.01(\mathrm{~d}, J=8.5 \mathrm{~Hz}, 1 \mathrm{H}) .{ }^{13} \mathrm{C} \mathrm{NMR}\left(101 \mathrm{MHz}, \mathrm{DMSO}-d_{6}\right)$ $\delta 166.61,154.15,133.43,130.68,122.82$.

Diethyl 4,4'-(diazene-1,2-diyl)dibenzoate (3)<smiles>CCOC(=O)c1ccc(N=Nc2ccc(C(=O)OCC)cc2)cc1</smiles>

To a solution of 4,4'-(diazene-1,2-diyl)dibenzoic acid $2(3 \mathrm{~g}, 11.1 \mathrm{mmol})$ in ethanol $(200 \mathrm{~mL})$ was carefully added concentrated sulfuric acid $(2 \mathrm{~mL})$ and the resulting solution was refluxed for 48 hours under stirring. The solvent was then evaporated under vacuum and the residue was taken up with chloroform to dissolve the desired final compound, filtered to remove unreacted starting material and finally evaporated to afford diethyl 4,4'-(diazene-1,2-diyl)dibenzoate 3 (3.10 g, 86\% yield).

${ }^{1} \mathrm{H} \mathrm{NMR}\left(400 \mathrm{MHz}, \mathrm{CDCl}_{3}\right) \delta 8.34-8.12(\mathrm{~m}, 1 \mathrm{H}), 8.08-7.90(\mathrm{~m}, 1 \mathrm{H}), 4.43(\mathrm{q}, J=7.1 \mathrm{~Hz}, 1 \mathrm{H}), 1.43(\mathrm{t}, J=7.1$ $\mathrm{Hz}, 1 \mathrm{H}) .{ }^{13} \mathrm{C} \mathrm{NMR}\left(101 \mathrm{MHz}, \mathrm{CDCl}_{3}\right) \delta 166.08,155.03,132.91,130.77,123.02,61.51,14.49$. 


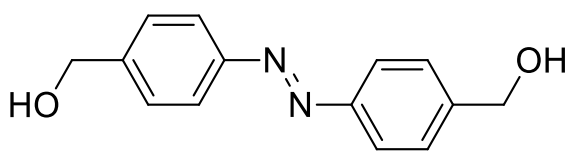

To a solution of diethyl 4,4'-(diazene-1,2-diyl)dibenzoate $3(1.35 \mathrm{~g}, 4.14 \mathrm{~mol})$ in anhydrous THF (50 mL) was slowly added lithium aluminum hydride $(392.50 \mathrm{mg}, 10.34 \mathrm{~mol})$ at $-10{ }^{\circ} \mathrm{C}$ and the resulting mixture was stirred at room temperature for 20 minutes (the reaction mixture turns brown). After cooling, excess lithium aluminum hydride was neutralized at $0{ }^{\circ} \mathrm{C}$ with ice water, and the aqueous phase was extracted three times with $50 \mathrm{~mL}$ of EtOAc. The combined organic layers were washed with brine, dried over $\mathrm{MgSO}_{4}$ and finally evaporated under vacuum to provide 4-(4'-hydroxyphenylazo)benzyl alcohol $\mathbf{4}$ as an orange solid. (990 mg, $99 \%$ yield).

m.p.: $231^{\circ} \mathrm{C}$

${ }^{1} \mathrm{H}$ NMR $\left(400 \mathrm{MHz}\right.$, DMSO- $\left.d_{6}\right): \delta 7.86(\mathrm{~d}, J=8.3 \mathrm{~Hz}, 4 \mathrm{H}), 7.53(\mathrm{~d}, J=8.3 \mathrm{~Hz}, 4 \mathrm{H}), 5.37(\mathrm{t}, J=5.7 \mathrm{~Hz}, 2 \mathrm{H}), 4.60$ $(d, J=5.7 \mathrm{~Hz}, 4 \mathrm{H}) .{ }^{13} \mathrm{C}$ NMR $\left(101 \mathrm{MHz}, \mathrm{DMSO}-d_{6}\right): \delta 150.85,146.25,127.11,122.35,62.44$.

\section{4,4'-Bis(bromomethyl)azobenzene (5) [Route A]}

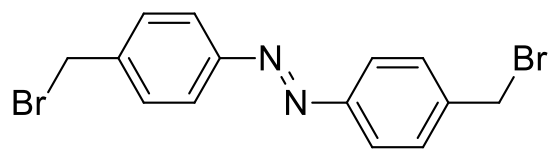

To a cooled solution of 4 (900 $\mathrm{mg}, 3.71 \mathrm{mmol})$ and $\mathrm{N}$-bromosuccinimide $(3.31 \mathrm{~g}, 18.57 \mathrm{mmol})$ in anhydrous THF $(60 \mathrm{~mL})$, a solution of triphenylphosphine $(4.87 \mathrm{~g}, 18.57 \mathrm{mmol})$ in anhydrous THF $(20 \mathrm{~mL})$ was slowly added at $0{ }^{\circ} \mathrm{C}$. The reaction mixture was then allowed to warm up at room temperature and stirred for 1 hour. The reaction was monitored through silica gel TLC (eluent: DCM). After 1 hour, the solvent was evaporated under vacuum and the resulting residue was purified via flash chromatography on silica gel (100\% DCM) to afford 5 as an orange solid ( $1.00 \mathrm{~g}, 73 \%$ yield).

m.p.: $228-230^{\circ} \mathrm{C}$

${ }^{1} \mathrm{H}$ NMR $\left(400 \mathrm{MHz}, \mathrm{CDCl}_{3}\right) \delta 7.90(\mathrm{~d}, J=8.4 \mathrm{~Hz}, 4 \mathrm{H}), 7.54(\mathrm{~d}, J=8.3 \mathrm{~Hz}, 4 \mathrm{H}), 4.56(\mathrm{~s}, 4 \mathrm{H}) .{ }^{13} \mathrm{C} \mathrm{NMR}(101 \mathrm{MHz}$, $\left.\mathrm{CDCl}_{3}\right): \delta 152.42,140.93,130.06,123.51,32.83$. 


\section{4,4'-Bis(bromomethyl)azobenzene (5) [Route B]}

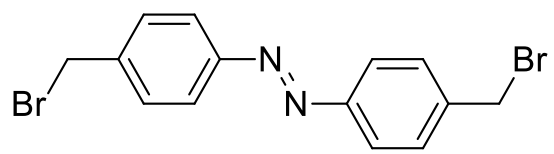

A solution 4,4'-dimethylazobenzene $7\left(966 \mathrm{mg}, 4.59 \mathrm{mmol}\right.$, prepared as reported by Velema et al., ${ }^{4}$ and $\mathrm{N}$ bromosuccinimide $(1.72 \mathrm{~g}, 9.65 \mathrm{mmol})$ in MeCN $(10 \mathrm{~mL})$ was stirred at room temperature under white light illumination (Dolan-Jenner Fiber-Lite Mi-150 Fiber Optic Illuminator, $150 \mathrm{~W}$ ) for 24 hours. The obtained orange solid was then filtered and washed several times with $\mathrm{MeOH}$. The resulting solid was dried under vacuum and further purified via flash chromatography (100\% DCM) to afford 3 as an orange solid (1.2 g, 71\% yield).

M.p.: $228-230^{\circ} \mathrm{C}$

${ }^{1} \mathrm{H}$ NMR $\left(400 \mathrm{MHz}, \mathrm{CDCl}_{3}\right): \delta 7.90(\mathrm{~d}, J=8.4 \mathrm{~Hz}, 4 \mathrm{H}), 7.54(\mathrm{~d}, J=8.3 \mathrm{~Hz}, 4 \mathrm{H}), 4.56(\mathrm{~s}, 4 \mathrm{H}) .{ }^{13} \mathrm{C} \mathrm{NMR}(101 \mathrm{MHz}$, $\left.\mathrm{CDCl}_{3}\right): \delta 152.42,140.93,130.06,123.51,32.83$.

\section{$N$-(4-((4-(bromomethyl)phenyl)diazenyl)benzyl)-3-(1,3-dioxoisoindolin-2-yl)-N,N-dimethylpropan-1- aminium bromide (9)}<smiles>C[N+](C)(Br)CCCN1C(=O)c2ccccc2C1=O</smiles>

Compound 8 (50 mg, $0.22 \mathrm{mmol})$ and $3(1.19 \mathrm{~g}, 3.23 \mathrm{mmol})$ were dissolved in MeCN (30 mL) and stirred for 3 hours at $60{ }^{\circ} \mathrm{C}$. Reaction was monitored with silica gel TLC $\left(R_{\mathrm{f}}=0.12\right.$, DCM:MeOH 9:1, Dragendorff). The reaction mixture was then concentrated under reduced pressure and the residue was purified by column chromatography on silica gel (eluent: $\mathrm{DCM} / \mathrm{MeOH}, 8: 2$ ) followed by recrystallization from $\mathrm{MeCN} / \mathrm{Et}_{2} \mathrm{O}$. The precipitate was dried in vacuo to give the desired product 9 as an orange hygroscopic solid ( $52 \mathrm{mg}, 40 \%$ yield).

${ }^{1} \mathrm{H}$ NMR $\left(400 \mathrm{MHz}, \mathrm{CD}_{3} \mathrm{OD}\right): \delta 7.98-7.89(\mathrm{~m}, J=8.8 \mathrm{~Hz}, 4 \mathrm{H}), 7.87(\mathrm{dd}, J=5.5,3.1 \mathrm{~Hz}, 2 \mathrm{H}), 7.80(\mathrm{dd}, J=5.5$, $3.1 \mathrm{~Hz}, 2 \mathrm{H}), 7.74(\mathrm{~d}, J=8.5 \mathrm{~Hz}, 2 \mathrm{H}), 7.64(\mathrm{~d}, J=8.4 \mathrm{~Hz}, 2 \mathrm{H}), 4.68(\mathrm{~s}, 2 \mathrm{H}), 4.67(\mathrm{~s}, 2 \mathrm{H}), 3.83(\mathrm{t}, J=6.3 \mathrm{~Hz}, 2 \mathrm{H})$, $3.48-3.40(\mathrm{~m}, 2 \mathrm{H}), 3.14(\mathrm{~s}, 6 \mathrm{H}), 2.37-2.25(\mathrm{~m}, 2 \mathrm{H}) .{ }^{13} \mathrm{C} N M R\left(101 \mathrm{MHz}, \mathrm{CD}_{3} \mathrm{OD}\right): \delta$ 169.80, 154.98, 153.39, 143.78, 135.57, 135.15, 133.32, 131.29, 124.42, 124.35, 124.32, 68.52, 63.12, 50.81, 35.66, 33.00, 23.53.

LC-MS (QMS, [M + H] $]^{+}$): calcd for $\mathrm{C}_{27} \mathrm{H}_{28} \mathrm{BrN}_{4} \mathrm{O}_{2}{ }^{+}, 519.14$ and 521.14; found 519.3 and 521.2. 


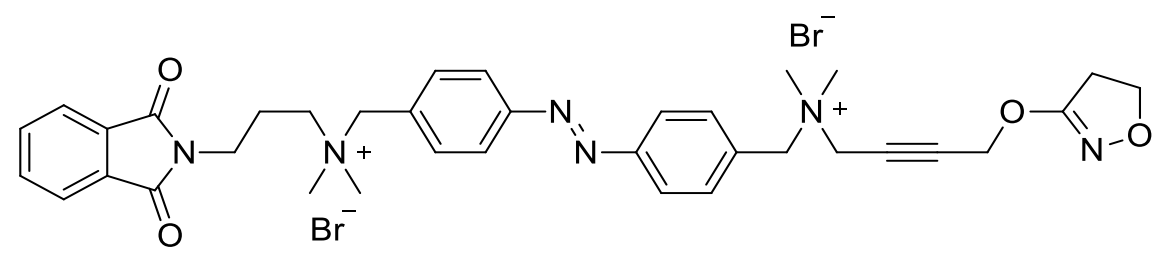

Compound 9 ( $38 \mathrm{mg}, 0.06 \mathrm{mmol}$ ) and 10 (23.67 mg, $0.127 \mathrm{mmol}$ ) were dissolved in MeCN (10 mL) and stirred at r.t. for 24 hours. Reaction progress was controlled by silica gel TLC to monitor the disappearance of the starting material. The final mixture was then concentrated under reduced pressure and the residue was purified by RP-HPLC to afford 1 as an orange hygroscopic solid (27 mg, 55\%).

${ }^{1} \mathrm{H}$ NMR $\left(400 \mathrm{MHz}, \mathrm{CD}_{3} \mathrm{OD}\right) \delta 8.10(\mathrm{~d}, J=8.5 \mathrm{~Hz}, 2 \mathrm{H}), 8.02(\mathrm{~d}, J=8.5 \mathrm{~Hz}, 2 \mathrm{H}), 7.90(\mathrm{dd}, J=5.6,3.0 \mathrm{~Hz}, 2 \mathrm{H}), 7.85$ $(\mathrm{d}, J=8.5 \mathrm{~Hz}, 2 \mathrm{H}), 7.82(\mathrm{dd}, J=5.6,3.0 \mathrm{~Hz}, 2 \mathrm{H}), 7.75(\mathrm{~d}, J=8.5 \mathrm{~Hz}, 2 \mathrm{H}), 4.99(\mathrm{t}, J=1.6 \mathrm{~Hz}, 2 \mathrm{H}), 4.74(\mathrm{~s}, 2 \mathrm{H})$, $4.64(\mathrm{~s}, 2 \mathrm{H}), 4.41(\mathrm{t}, J=9.6 \mathrm{~Hz}, 2 \mathrm{H}), 4.35(\mathrm{t}, J=1.7 \mathrm{~Hz}, 2 \mathrm{H}), 3.84(\mathrm{t}, J=6.3 \mathrm{~Hz}, 2 \mathrm{H}), 3.47-3.38(\mathrm{~m}, 2 \mathrm{H}), 3.22(\mathrm{~s}$, $6 \mathrm{H}), 3.11(\mathrm{~s}, 6 \mathrm{H}), 3.07(\mathrm{t}, J=9.6 \mathrm{~Hz}, 2 \mathrm{H}), 2.37-2.24(\mathrm{~m}, 2 \mathrm{H}) .{ }^{13} \mathrm{C} \mathrm{NMR}\left(101 \mathrm{MHz}, \mathrm{CD}_{3} \mathrm{OD}\right) \delta 169.79,168.80$, $163.40,163.05,162.71,154.99,154.83,135.56,135.28,124.70,124.54,124.31,88.78,76.82,71.22,68.47$, $67.39,63.24,58.29,54.94,50.90,50.76,35.65,33.66,23.51$.

$\mathrm{RT}(\mathrm{HPLC}-\mathrm{PDA})=6.24 \mathrm{~min}$ (cis isomer), $6.67 \mathrm{~min}$ (trans isomer); purity $\geq 95 \%$ (Figure S1.1).

HR-MS (ESI, $[\mathrm{M}+\mathrm{H}]^{+}$): calcd for $\mathrm{C}_{36} \mathrm{H}_{42} \mathrm{~N}_{6} \mathrm{O}_{4}{ }^{2+}, 311.16$; found 311.1625 (Figure S1.2). 


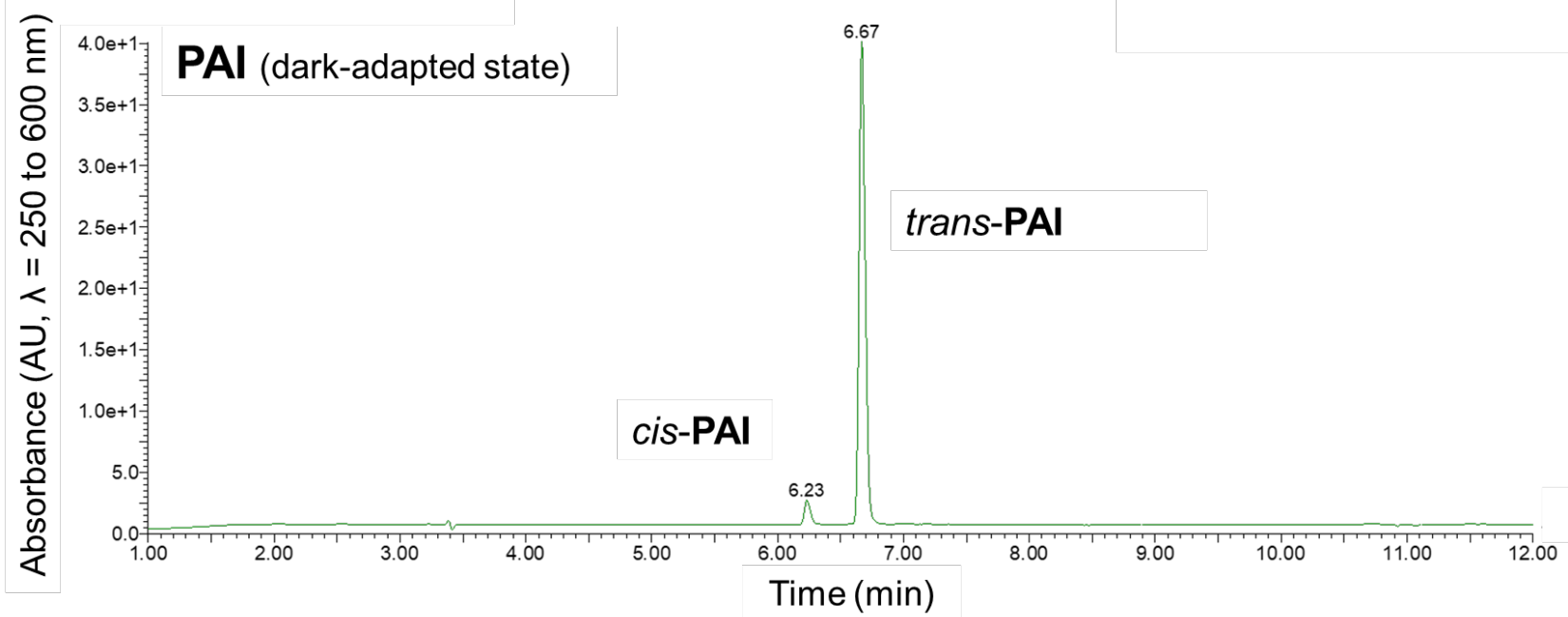

Figure S1.1. HPLC chromatogram of PAI as obtained under benchtop conditions (PDA detector from 250 to $600 \mathrm{~nm}$; compound purity $\geq 95 \%)$.

Full MS (150-1000 Da)

Z:Instrumentsi...12804_FR_PAI_av90

nกinar17 19-na-11

2804_FR_PAI

$\mathrm{MeOH} / \mathrm{H} 2 \mathrm{O} / \mathrm{FA}$

2804_FR_PA_av90 \#1 RT: 24.67 AV: 1 NL: 9.7

T: FTMS + p NSI Full ms [150.00-1000.00]

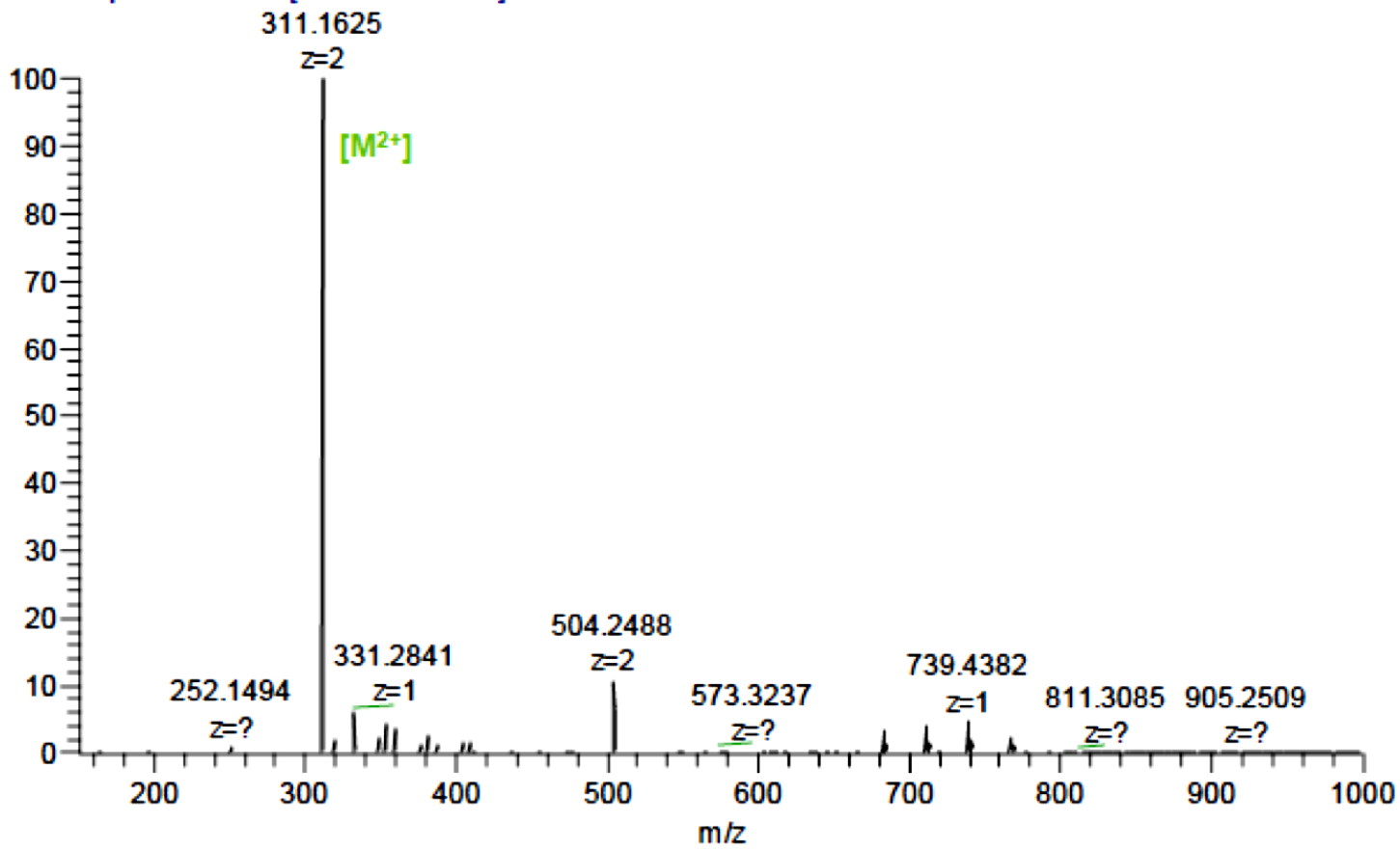

Figure S1.2. Full high-resolution mass spectrum of PAI (positive ionization). 


\section{Photochemical characterization}

An essential requirement for using PAI as a light-dependent activator of $\mathrm{M} 2 \mathrm{mAChRs}$ is that it effectively responds to light, which means that it can be quickly photo-isomerized (from trans to cis and vice versa) between two different conformations with a relatively high degree of photoconversion (trans/cis ratio). To this end, we first characterized PAI by UV/Vis spectroscopy. As expected, it revealed a clear photochromic behavior with the typical absorption bands of azobenzenes. Maximum absorption peaks in aqueous solution were observed at around $315 \mathrm{~nm}$ and $430 \mathrm{~nm}$ and are due to the $\pi-\pi^{*}$ and $n-\pi^{*}$ transitions, respectively, which allows for distinct photoswitching between the trans and cis isomers (Figure S2.1, panel A). PAI can be effectively isomerized from trans to cis with ultraviolet light (365 nm), and back-isomerized from cis to trans with white or blue $(460 \mathrm{~nm})$ light. The process is reversible and can be repeated several times without any noticeable loss of photochromic behavior (Figure S2.1, panel B).

We next quantified by ${ }^{1} \mathrm{H}-\mathrm{NMR}$ and HPLC analysis the ratio between the two isomers at the photostationary state (Figure S2.2). The amount of the thermodynamically less stable cis isomer shifted from an initial value of $13 \%$ (as obtained under benchtop conditions) to 73\% upon irradiation with $365 \mathrm{~nm}$ light for 10 minutes. Moreover, PAI showed an excellent thermal stability at the photostationary state achieved after ultraviolet irradiation. It was stable for more than 2 hours in aqueous solution at $37^{\circ} \mathrm{C}$ in the dark, and could be effectively reconverted to a photostationary state in favor of the trans isomer after illumination with white light (Figure S2.3). Such thermal stability allowed to conveniently study the two different photostationary states of PAI in a relatively large timescale.
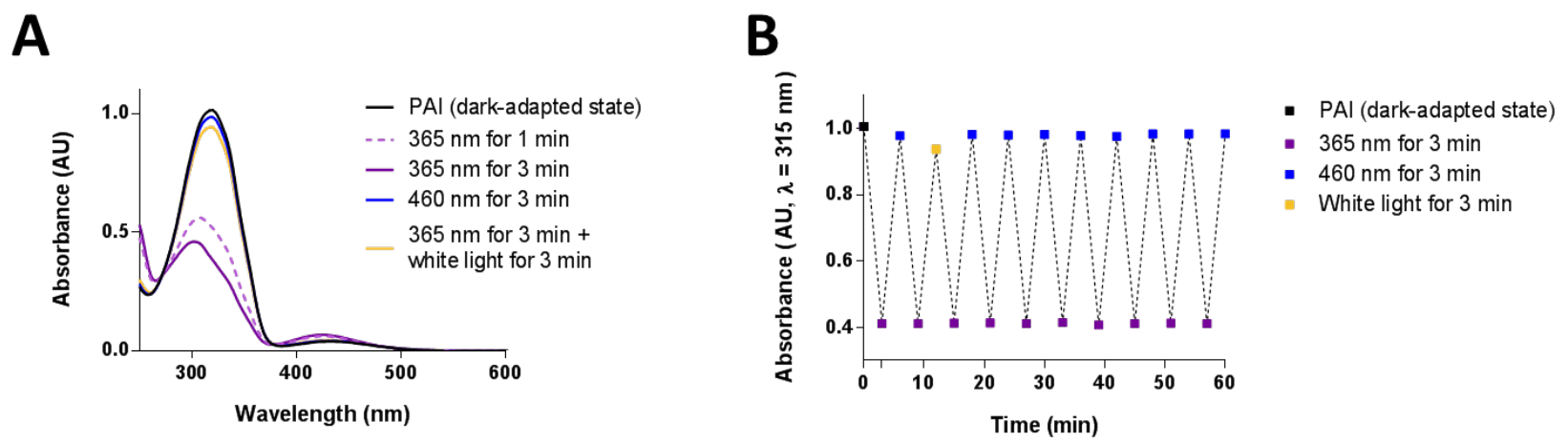

Figure S2.1. Photochromic properties of PAI. A) Absorption spectra of PAI ( $30 \mu \mathrm{M}$ in $\left.\mathrm{H}_{2} \mathrm{O}\right)$. B) Reversibility and stability of the photochromic behavior of PAI over several cycles of isomerization. 
A

PAI (dark-adapted state)

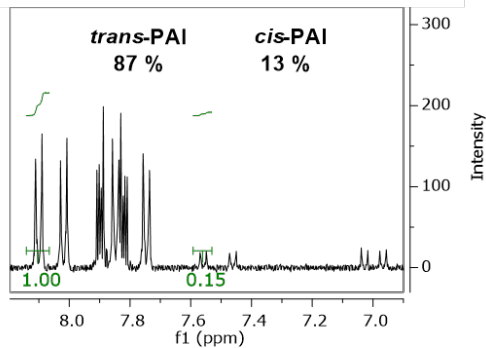

PAl (365 nm, $10 \mathrm{~min})$

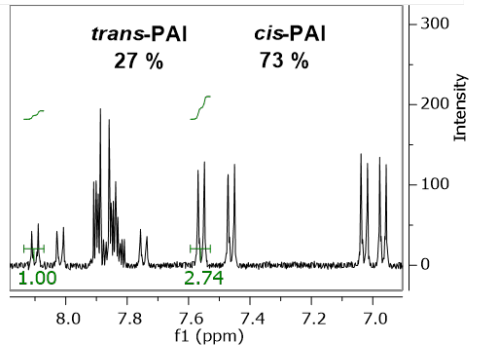

PAl (white light, $10 \mathrm{~min}$ )

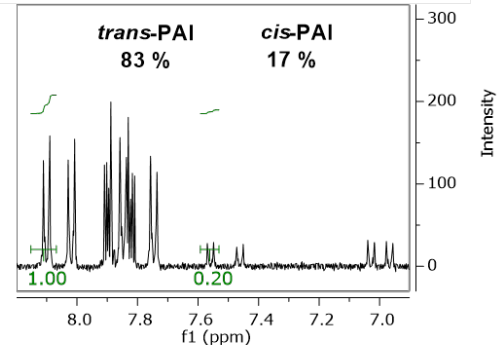

B
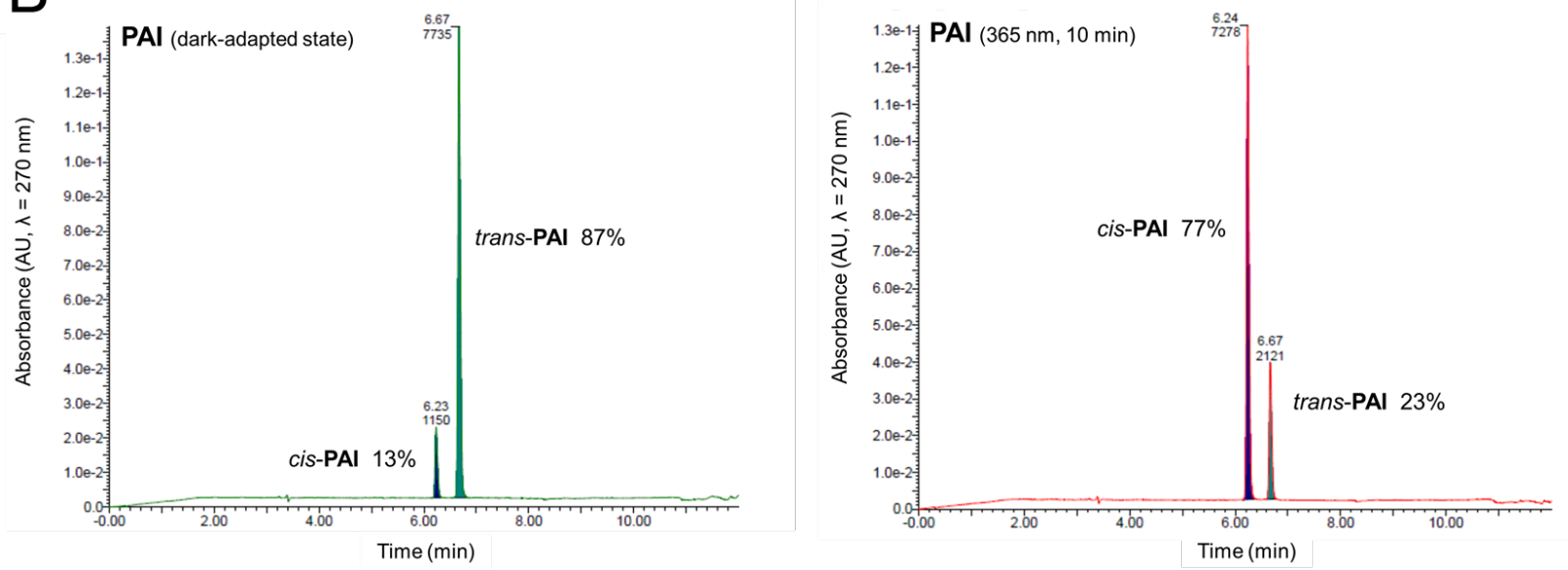

Figure S2.2. Quantification of the PSS by ${ }^{1} \mathrm{H}-\mathrm{NMR}$ (panel A) and HPLC (panel B) analysis, showing the ratio between the two isomers as obtained under benchtop conditions and after 10 minutes of irradiation with $365 \mathrm{~nm}$ light and white light.

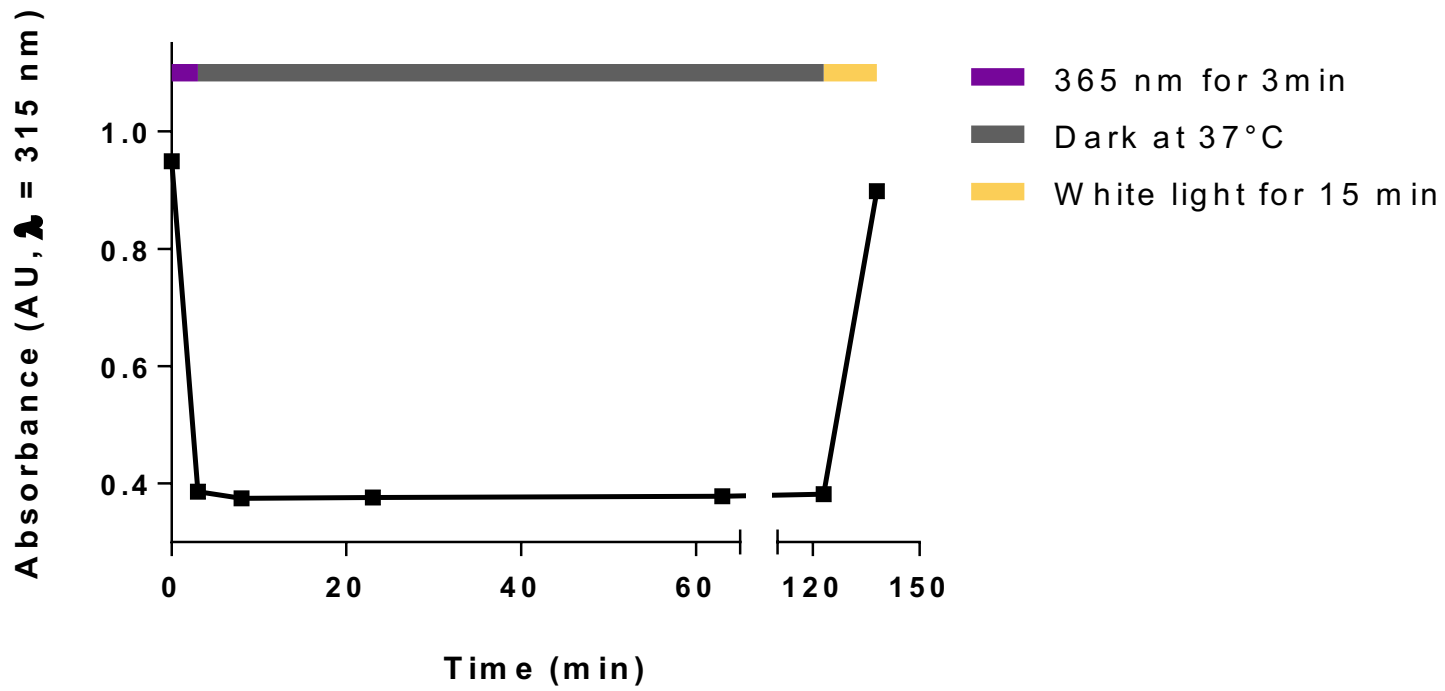

Figure S2.3. Thermal stability of PAI. The photostationary state (PSS) achieved after irradiation with $365 \mathrm{~nm}$ light in aqueous solution $(30 \mu \mathrm{M})$ is stable for more than 2 hours at $37^{\circ} \mathrm{C}$ in the dark. Irradiation with white light allows to regain a PPS in favor of the trans isomer. 


\section{NMR spectroscopy}

\section{PAl (dark-adapted state)}

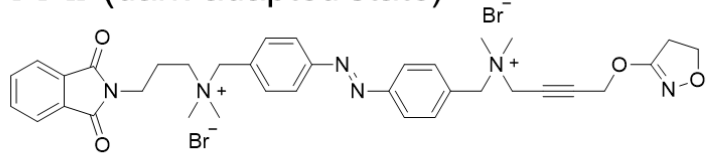

${ }^{1} \mathrm{H}$ NMR (400 MHz, CD 30 OD): $\delta 8.10(\mathrm{~d}, J=8.5 \mathrm{~Hz}, 2 \mathrm{H}), 8.02(\mathrm{~d}, J=8.5 \mathrm{~Hz}$, $2 \mathrm{H}), 7.90$ (dd, $J=5.6,3.0 \mathrm{~Hz}, 2 \mathrm{H}$ ), 7.85 (d, $J=8.5 \mathrm{~Hz}, 2 \mathrm{H}$ ), 7.82 (dd, $J=5.6$, $3.0 \mathrm{~Hz}, 2 \mathrm{H}), 7.75(\mathrm{~d}, J=8.5 \mathrm{~Hz}, 2 \mathrm{H}), 4.99(\mathrm{t}, J=1.6 \mathrm{~Hz}, 2 \mathrm{H}), 4.74(\mathrm{~s}, 2 \mathrm{H})$, $4.64(\mathrm{~s}, 2 \mathrm{H}), 4.41(\mathrm{t}, J=9.6 \mathrm{~Hz}, 2 \mathrm{H}), 4.35(\mathrm{t}, J=1.7 \mathrm{~Hz}, 2 \mathrm{H}), 3.84(\mathrm{t}, J=6.3$ $\mathrm{Hz}, 2 \mathrm{H}), 3.47-3.38(\mathrm{~m}, 2 \mathrm{H}), 3.22(\mathrm{~s}, 6 \mathrm{H}), 3.11(\mathrm{~s}, 6 \mathrm{H}), 3.07(\mathrm{t}, J=9.6 \mathrm{~Hz}$, $2 \mathrm{H}), 2.37-2.24(\mathrm{~m}, 2 \mathrm{H})$.

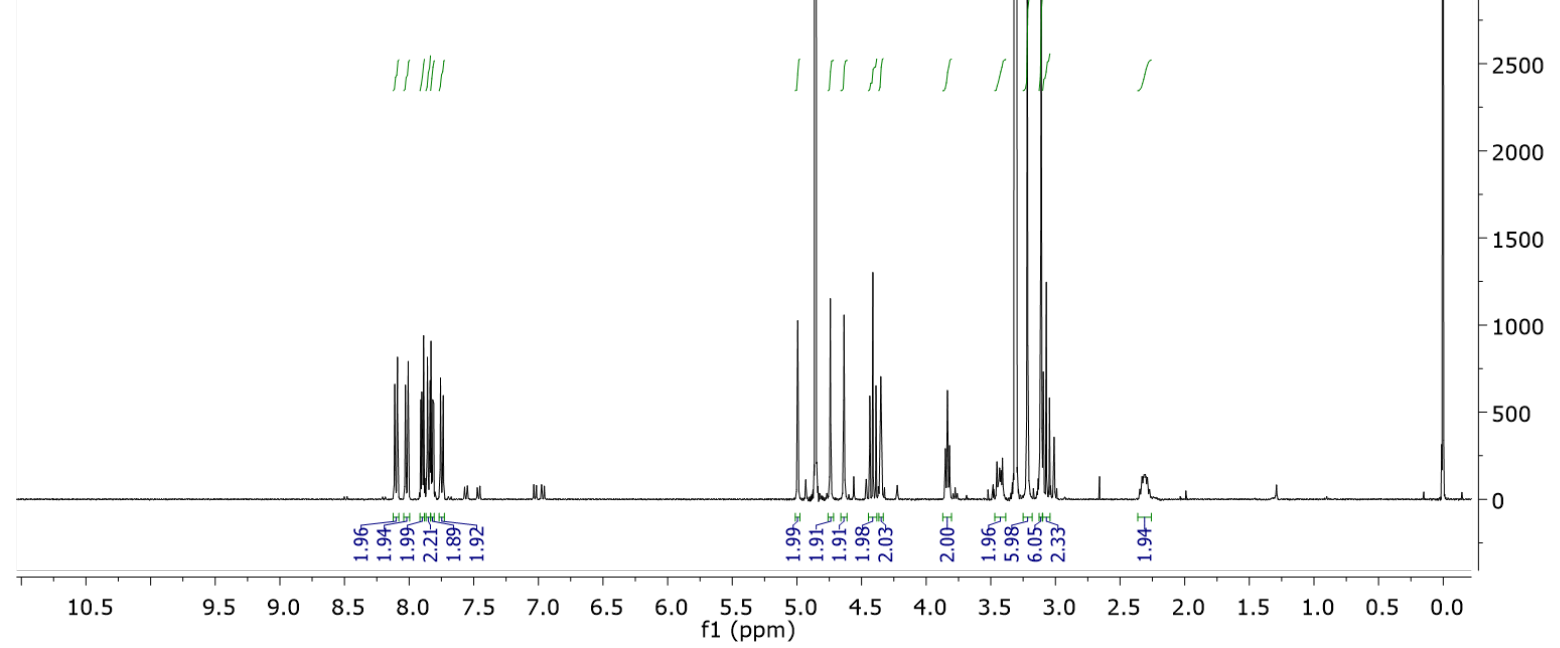

Figure S3.1. ${ }^{1} \mathrm{H}-\mathrm{NMR}$ of PAl as obtained under benchtop conditions.

PAI (dark-adapted state)

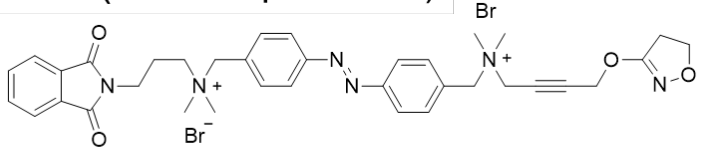

${ }^{13}$ C NMR (101 MHz, CD OD): $\delta 169.79,168.80,163.40,163.05,162.71$ $154.99,154.83,135.56,135.28,124.70,124.54,124.31,88.78,76.82$
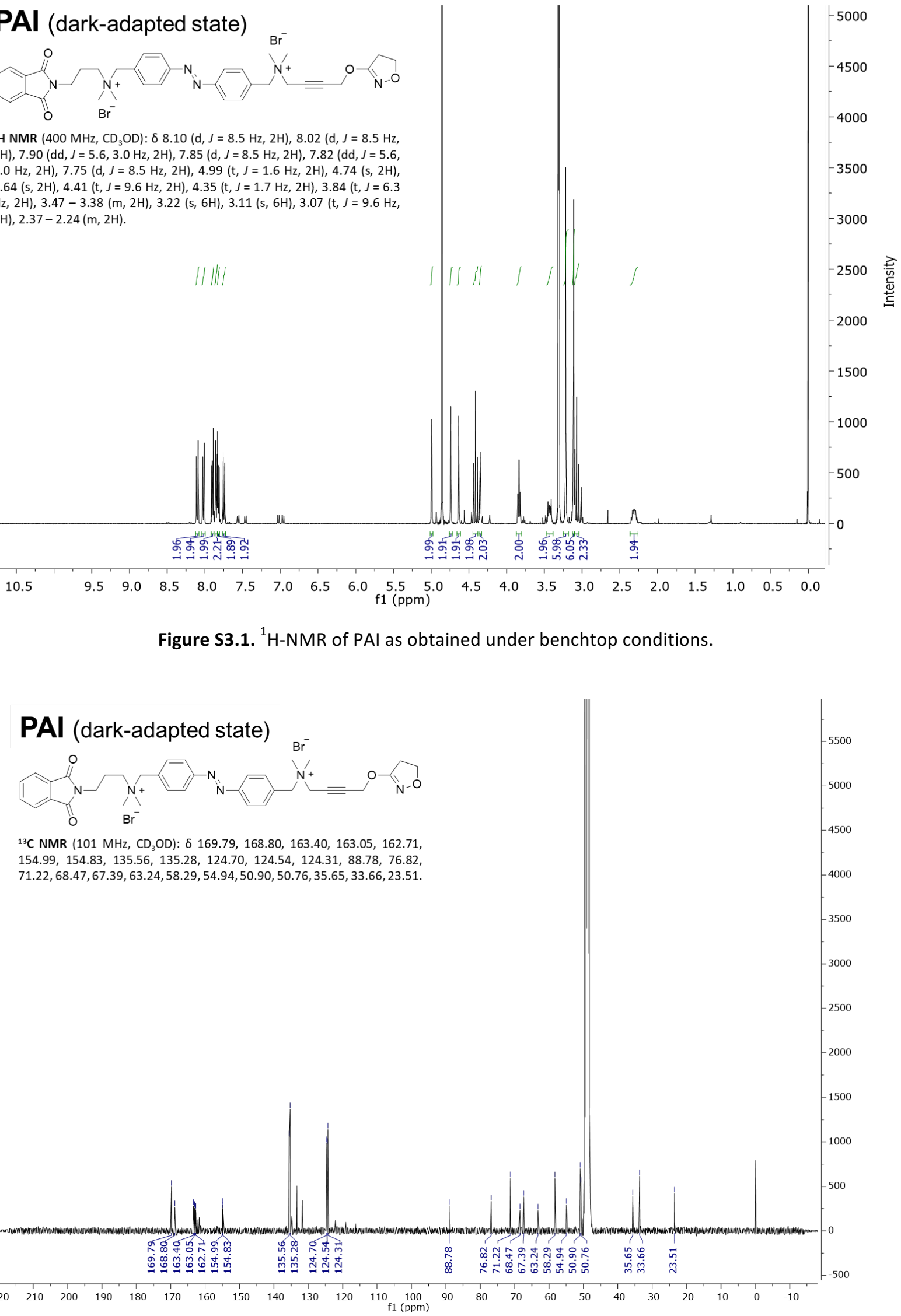

Figure S3.2. ${ }^{13} \mathrm{C}-\mathrm{NMR}$ of PAI as obtained under benchtop conditions. 


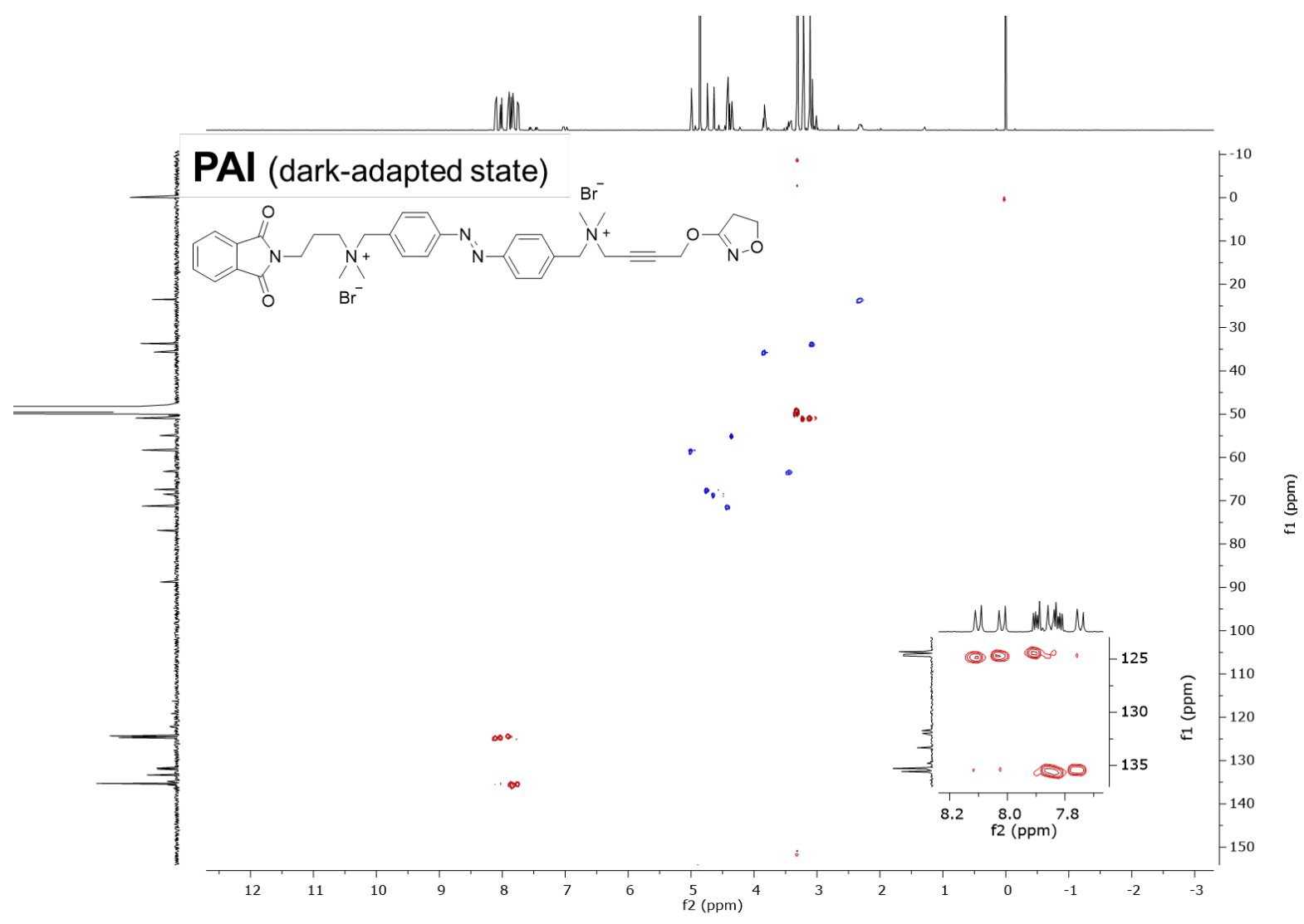

Figure S3.3. gCOSY of PAI as obtained under benchtop conditions.

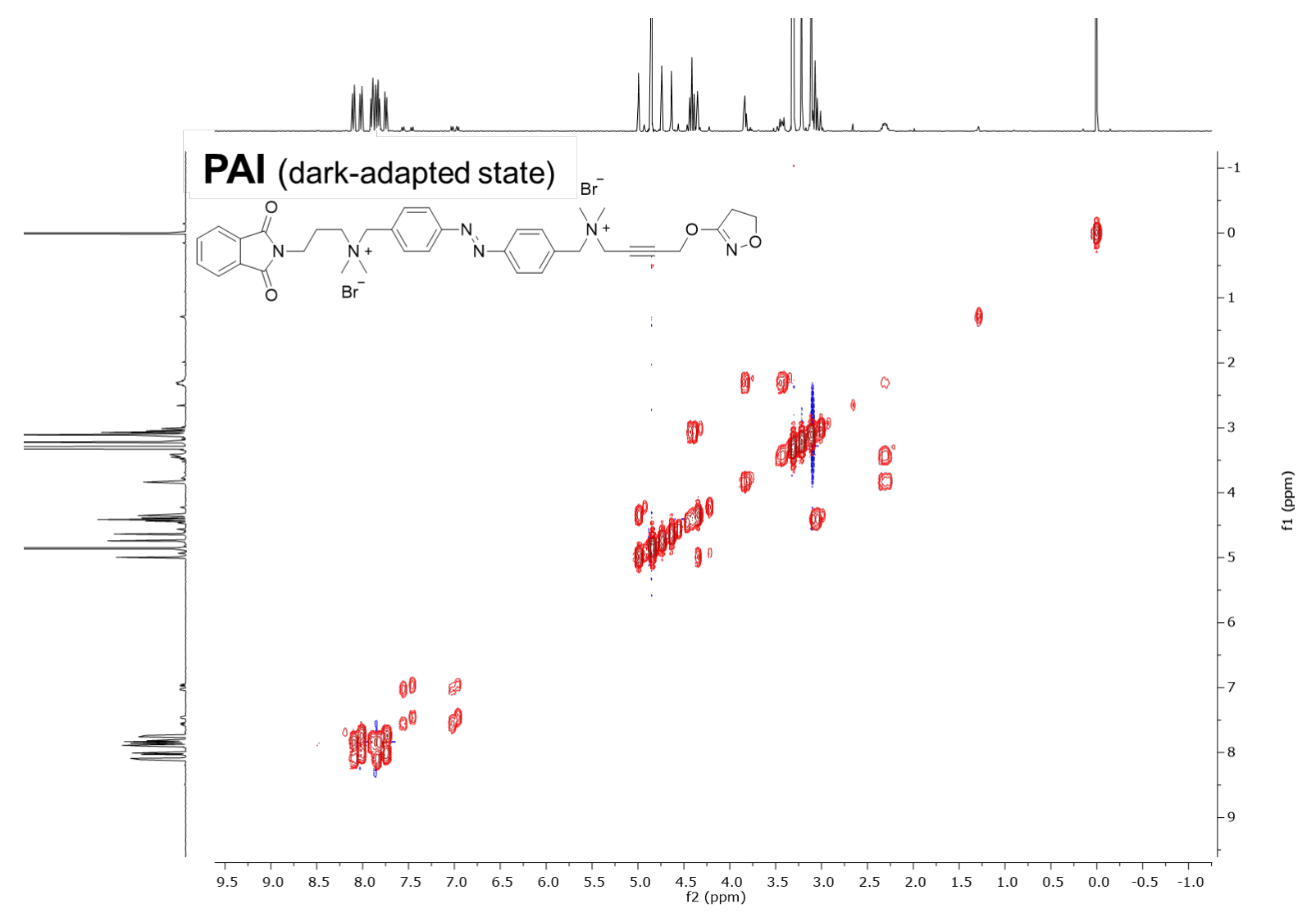

Figure S3.4. HSQC of PAI as obtained under benchtop conditions. 


\section{In vitro calcium imaging experiments}

\subsection{Materials and methods}

Cell culture and transfection. HEK tsA201 cells were maintained at $37{ }^{\circ} \mathrm{C}$ in a humidified atmosphere with $5 \% \mathrm{CO}_{2}$ and grown in Dulbecco's Modified Eagle's Medium/Nutrient Mixture F-12 Ham (DMEM/F12 1:1, Life Technologies) medium, supplemented with $10 \%$ fetal bovine serum (FBS, Life Technologies) and antibiotics (1\% penicillin/streptomycin, Sigma-Aldrich). Co-expression of human muscarinic acetylcholine receptor $\mathrm{M} 2$ (Addgene) and chimeric $\mathrm{G}_{\mathrm{i}} / \mathrm{G}_{\mathrm{q}}$ protein (GqTOP) (ratio 1:1) was induced by plasmid transient transfection with X-tremeGENE 9 DNA Transfection Reagent (Roche Applied Science) following the manufacturer's instructions. ${ }^{7}$ The day after transfection, cells were harvested with accutase (Sigma-Aldrich) and seeded onto 16-mm glass coverslips (Fisher Scientific) pretreated with collagen (Sigma-Aldrich) to allow cell adhesion. Preconfluent cultures were used for experiments between $48 \mathrm{~h}$ and $72 \mathrm{~h}$ after transfection.

In vitro single-cell calcium imaging. The bath solution used for single cell intracellular calcium recordings contained: $140 \mathrm{mM} \mathrm{NaCl}, 5.4 \mathrm{mM} \mathrm{KCl}, 1 \mathrm{mM} \mathrm{MgCl}$, $10 \mathrm{mM}$ HEPES, $10 \mathrm{mM}$ glucose and $2 \mathrm{mM} \mathrm{CaCl}_{2}$, and was adjusted to $\mathrm{pH} 7.4$ with $\mathrm{NaOH}$. Before each experiment, cells were mounted on the recording chamber (Open Diamond Bath Imaging Chamber for Round Coverslips from Warner Instruments) and loaded with the calcium indicator Oregon Green BAPTA-1, AM (OGB-1AM) (Life Technologies) for 30 min at $37{ }^{\circ} \mathrm{C}$ and $5 \% \mathrm{CO}_{2}$, at a final concentration of $10 \mu \mathrm{M}$ in $\mathrm{Ca}^{2+}$-free bath solution. Cells were rinsed with fresh solution, and the recording chamber was filled with $1 \mathrm{~mL}$ recording solution. Calcium imaging was performed on an IX71 inverted microscope (Olympus) with a XLUMPLFLN 20XW x20/1 water immersion objective (Olympus).

OGB-1 AM was excited during $8 \mathrm{~ms}$ at $488 \mathrm{~nm}$ using a Polychrome $V$ monochromic light source (Till Photonics) equipped with a Xenon Short Arc lamp (Ushio) and a $505 \mathrm{~nm}$ dichroic beam splitter (Chroma Technology). Emission at $526 \mathrm{~nm}$ was filtered by a D535/40nm emission filter (Chroma Technology) and finally collected by a C9100-13 EM-CCD camera (Hamamatsu).

Images were acquired at room temperature with an imaging interval of 4 seconds with the SmartLux software (HEKA), and the imaging analysis was done with FIJI (ImageJ).

Drug application and photoswitching assays. Addition of agonists was carried out by carefully pipetting $50 \mu \mathrm{L}$ of the initial 200 pM solution of the compound directly into the accessory pool of the recording chamber for a final dilution of approximately 1:20.

Iperoxo, a previously described muscarinic selective superagonist, ${ }^{2}$ was used as a positive control to stimulate mAChRs in HEK tsA201 cells (30 pM).

Photostimulation during recordings was done by illumination of the entire focused field using the Polychrome $\checkmark$ connected to a personal computer, and shutter and wavelength were controlled using Patchmaster software (HEKA). Light intervals lasted a total of 5 minutes for all the HEK cell experiments, with flashes of blue (460 nm, 3.5-seconds duration) and UV (365 nm, 3.5-seconds duration) light. The light power measured with a Newport $1916-\mathrm{C}$ light meter placed after the objective was $16.48 \mathrm{~W} \cdot \mathrm{m}^{-2}$ for $488 \mathrm{~nm}, 4.94 \mathrm{~W} \cdot \mathrm{m}^{-2}$ for $365 \mathrm{~nm}$, and $15.92 \mathrm{~W} \cdot \mathrm{m}^{-2}$ for $460 \mathrm{~nm}$. 


\subsection{Control experiments}

In order to assess the significance of PAI (photo)responses in M2 mAChR expressing cells (Figure 2), further control experiments were performed in transfected cells in absence of PAI (Figure S4.1). No responses were observed under illumination at $365 \mathrm{~nm}$ and $460 \mathrm{~nm}$, which excludes any response artifacts due to light stimuli alone.

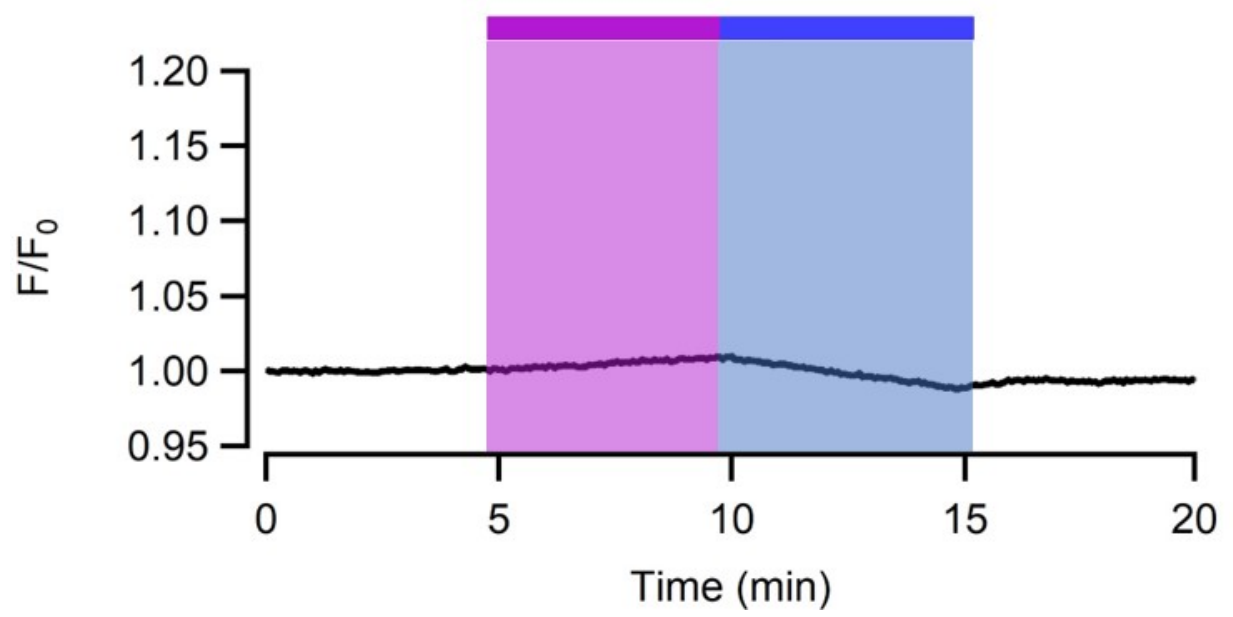

Figure S4.1. Real time calcium imaging traces from HEK cells incubated with $10 \mu \mathrm{M}$ of OGB-1AM for 30 min. The diagram shows the average trace of cells expressing M2-GqTOP in response to illumination at 365nm (purple bar) and 460nm (blue bar) $(n=34 \pm$ SEM).

\subsection{Receptor activation efficacy}

Direct cis-PAl isomer application at $10 \mathrm{pM}$ induce a response $50 \%$ lower than direct application of trans-PAI isomer. Application of the cis isomer at $30 \mathrm{pM}$ induced a response 10-fold lower compared to the trans isomer response at the same concentration (Figure S4.2). Moreover, residual responses upon application of the cis isomer can be attributed to the incomplete photoisomerization of the trans-isomer (trans/cis $=23: 77$ after $10 \mathrm{~min}$ at $365 \mathrm{~nm}$ ).
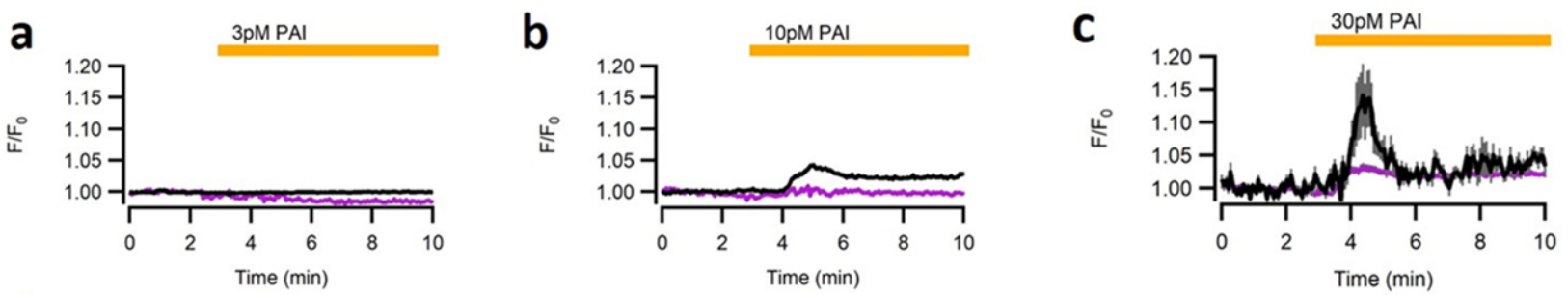

Figure S4.2. Real time calcium imaging traces from HEK cells expressing M2-GqTOP incubated with OGB-1AM (10 $\mu$ M for $30 \mathrm{~min}$ ). A) Average trace of cell response induced by the direct application of $3 \mathrm{pM}$ PAl (yellow bar) in its trans isoform (black line; $n=167$ ) or its cis isoform (purple line; $n=150$ ). B) Average trace of cell response induced by the direct application of 10 pM PAl in its trans isoform (black line; $n=296$ ) or its cis isoform (purple line; $n=150$ ). C) Average trace of cell response to 30 pM PAl in its trans isoform (black line; $n=8$ ) or its cis isoform (purple line; $n=230$ ). Gray shadow in the recording represents \pm SEM. 


\subsection{Receptor subtype selectivity}

Receptor subtype-selectivity of PAI (M2 against M1 mAChRs) has been studied by comparing amplitude of calcium signal response of cells expressing M2-GqTOP or M1 mAChR in presence of trans-PAl (10 pM). Human M1 mAChR (Addgene) was transfected as described in the Materials and methods section of the main text.

M2 mAChR transfected cells gave a significantly higher response than M1 mAChR expressing cells ( $8 \%$ for M1 against 33\% for $\mathrm{M} 2$ ). Data were normalized over the maximum response obtained with the nonselective orthosteric superagonist IPX at $30 \mathrm{pM}$. ( $t$-test of two samples assuming equal variances $p=0.00158$ ). 


\section{Molecular docking simulations}

\subsection{Materials and methods}

Molecular docking simulations were performed using the crystal structure of the human M2 muscarinic acetylcholine receptor retrieved from the Protein Data Bank (PDB code: 4MQT, chain A). ${ }^{8}$ To allow the docking of the dualsteric ligands into the active M2 AChR structure, the so called "tyrosine lid"9,10 was remodeled using rotamer libraries (UCSF Chimera) ${ }^{11}$ of the tyrosine residues involved (Tyr-104, Tyr-403, Tyr426). The protein pdb file was then prepared for docking by removing co-crystallized ligands, non-complexed ions and water molecules, and finally applying the Dock Prep tool available in the free software package UCSF Chimera. This involved the addition of hydrogens and assigning partial charges (AMBER ff14SB method). The structures of trans- and cis-PAl were built with standard bond length and angles using ChemDraw and then energy minimized with Chem3D by the MM2 method. The minimized compounds were further prepared for docking studies with UCSF Chimera by adding hydrogens and assigning partial charges (AMBER ff14SB method). The necessary pdbqt files of ligands and receptor were prepared using AutoDock 4.2 software. The docking studies were carried out using the standard docking protocol applied for AutoDock Vina in PyRx 0.8 virtual screening software. Autodock Vina has been reported to be an effective tool capable of quickly and accurately predicting bound conformations and binding energies of ligands with macromolecular targets. ${ }^{12,13}$ A grid box of size $10.08 \times 27.44 \times 28.96 \AA$, with $x, y$ and $z$ coordinates of $-2.98,-11.92$ and -12.00 , respectively, was fixed to cover the entire allosteric and orthosteric binding sites and accommodate the ligands to move freely. Docking studies were performed using an exhaustiveness value of 8 while all other parameters were maintained as defaults. All rotatable bonds within the ligands were allowed to rotate freely, and the receptor was considered rigid. The docking simulations were repeated three times for each ligand. The obtained poses were then ranked based on the predicted affinity docking scores $(\mathrm{kcal} / \mathrm{mol})$ and the best pose for each experiment was selected. The results were then analyzed using UCSF Chimera.

\subsection{Results and discussion}

We used molecular docking simulations in an attempt to rationalize the photoswitchable efficacy of PAI. Both isomers of the ligand were docked into their putative allosteric and orthosteric binding sites of the human M2 muscarinic acetylcholine receptor in its active conformation (PDB code: 4MQT, chain A). As previously reported, ${ }^{9}$ molecular docking of dualsteric ligands into the M2 mAChR required remodeling of the tyrosine lid (formed by Tyr-104, Tyr-403 and Tyr-426) which separates the orthosteric binding site from the allosteric binding site in the active conformation of the protein. To open this lid and put the two binding sites in communication, we selected different allowed conformers of each side chains while keeping all the other residues in their original position. Therefore, the only differences between the crystal structure and the obtained active-like receptor model were the side chain conformations of Tyr-104, Tyr-403 and Tyr-426. Trans-PAI and cis-PAI were docked at this receptor model using a standard docking protocol with AutoDock Vina in the PyRx 0.8 software with a suitable grid box. We ran three simulations for each ligand and selected the best pose obtained in each experiment based on the predicted binding affinity scores $(\mathrm{kcal} / \mathrm{mol})$. Best poses were superimposed into the $\mathrm{M} 2$ receptor model in the presence of the reference agonist Iperoxo (in its receptor-bound conformation) and analyzed using UCSF Chimera. The results of our in silico studies are presented in Table S1 and Figure S5.1.

In Iperoxo, key binding elements for agonist activity are (a) the positively charged nitrogen, which interacts with Asp-103 and displays $\pi$-cation interactions with Tyr-104, Tyr-403 and Tyr-426, (b) the triple bond, which exhibits hydrophobic contacts with Tyr-104, Trp-155 and Trp-400, and additionally (c) the oxygen of the 4,5dihydroisoxazole moiety, which forms a hydrogen bond with Asn- $404 .{ }^{10}$ Our simulations revealed a dualsteric binding topography of PAI in both configurations. The Iperoxo moiety of trans-PAl binds to the orthosteric binding site, with an orientation close to that observed for Iperoxo in the receptor-bound crystal structure 
and the key elements for agonist activity lying in proximity of those of the reference agonist, whereas the phthalimide moiety protrudes toward extracellular domains, likely engaging residues of the common allosteric binding site (Figure S5.1a). In agreement with our results, trans-PAI could therefore bind to the M2 mAChR in a dualsteric pose capable of inducing receptor activation. In contrast, cis-PAl appeared to bind preferentially in a flipped orientation, with the phthalimide group pointing out towards the orthosteric binding pocket and the 4,5-dihydroisoxazole moiety positioned in the allosteric binding site. Such a binding mode is not likely to form an active ligand-receptor complex and may justify the difference observed in terms of agonist efficacy between the two photo-isomers (Figure S5.1b).

\begin{tabular}{|c|c|c|}
\hline & trans-PAl (best pose) & \multicolumn{1}{c|}{ cis-PAl (best pose) } \\
\hline experiment number & \multicolumn{2}{|c|}{ binding affinity (kcal/mol) } \\
\hline $\mathbf{1}$ & -11.6 & -12.0 \\
\hline $\mathbf{2}$ & -11.6 & -11.8 \\
\hline $\mathbf{3}$ & -11.3 & -11.6 \\
\hline
\end{tabular}

Table S1. Binding affinity scores of the best poses for each of the docking studies performed with trans-and cis-PAI. 
a

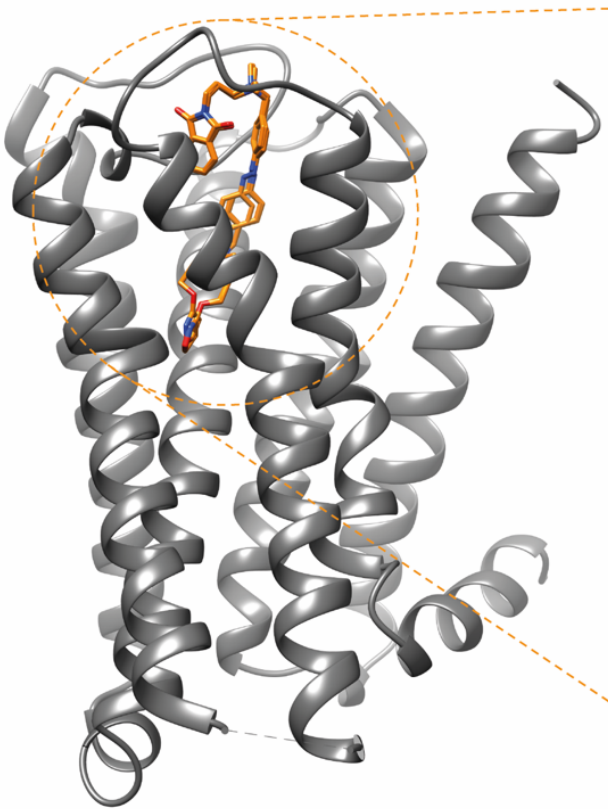

b

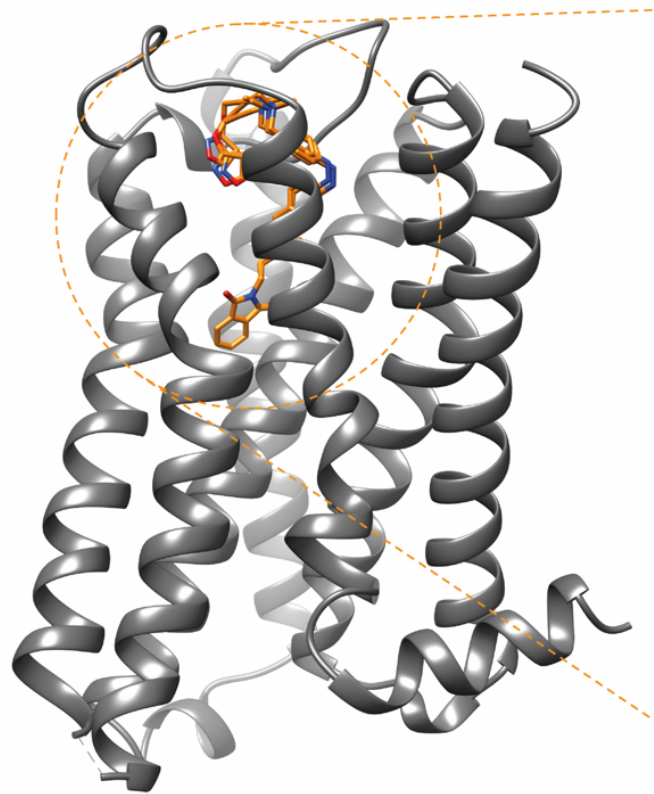

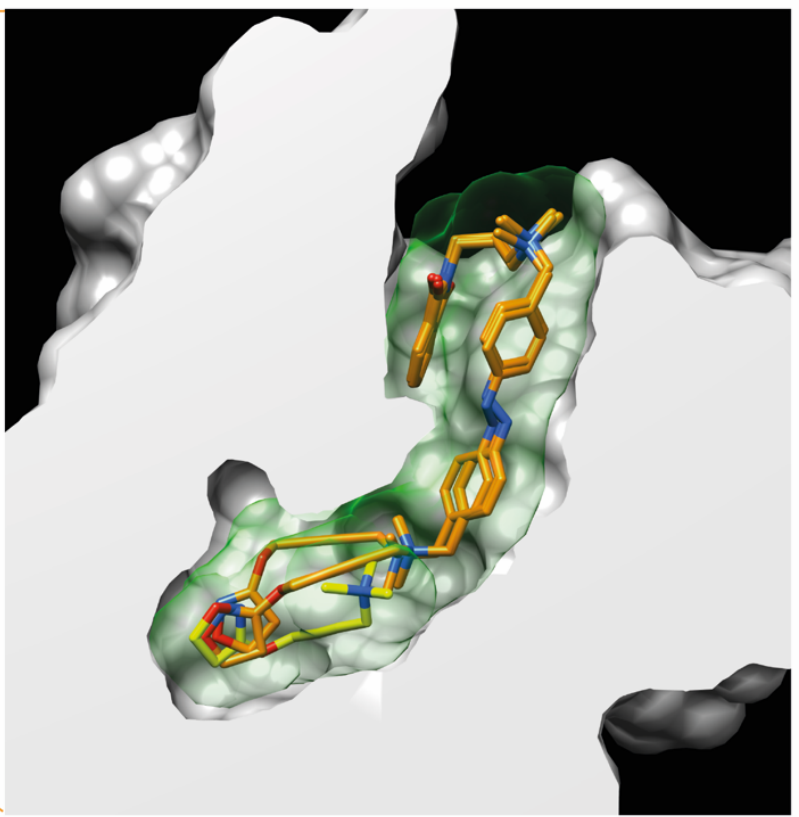

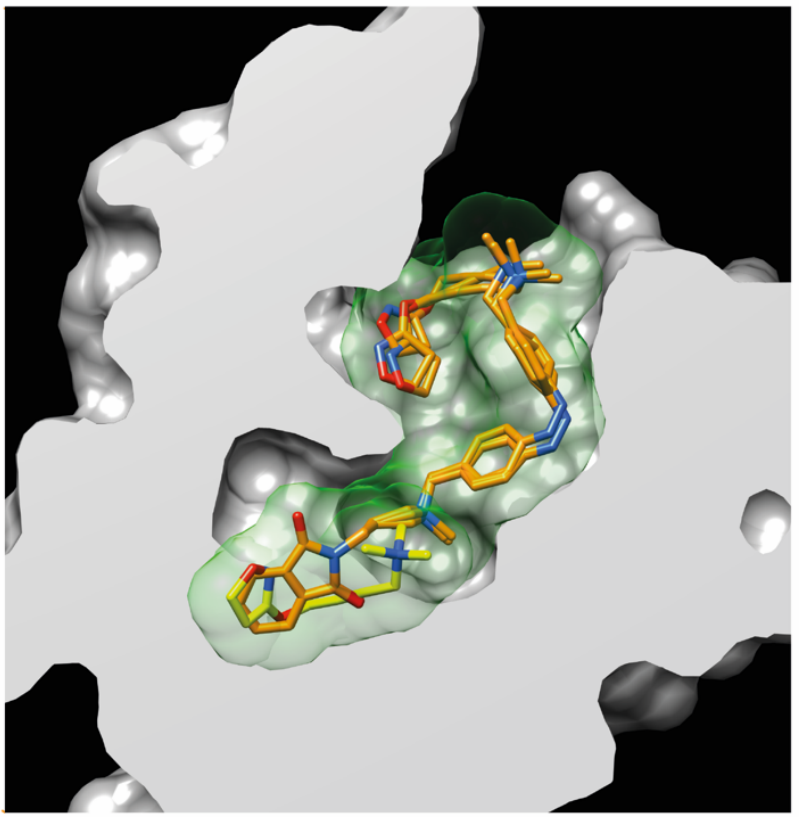

Figure S5.1 Hypothetical binding mode of trans-PAl and cis-PAl to a M2 mAChR model in its active state. Panels (a) and (b) show a full view (left side, ribbon-style representation) and a zoomed view (right side, hydrophobicity surface representation with sectioning) of the simulated ligand-receptor complexes. The reference orthosteric agonist Iperoxo, in yellow, appears in its receptor-bound conformation. Trans and cis-PAl are represented in orange. Nitrogen and oxygen atoms of the ligands are colored in blue and red, respectively. Our simulations revealed a dualsteric binding topography of PAl for both configurations, but, while the trans isomer seems to bind preferentially in an Iperoxo-like binding pose (Panel $a$ ), which is likely able to trigger receptor activation, the cis isomer shows preference for a flipped orientation (Panel $b$ ), which might be not compatible with the formation of active ligand-receptor complexes. 


\section{In vivo experiments in Xenopus tropicalis tadpoles}

\subsection{Materials and methods}

Animal housing. Xenopus tropicalis embryos (Nasco) were obtained by natural mating and maintained till 34 days post fertilization (dpf) in 0.1X Marc's modified Ringer's (MMR) solution in agarose coated Petri dishes $\left(10-15 \mathrm{~cm}\right.$ diameter) in a dark incubator $\left(24^{\circ} \mathrm{C}\right)$. Animals were transferred to tanks containing Xenopus water, which was prepared by adding $8 \mathrm{~g}$ of instant ocean salt (Instant Ocean) to $20 \mathrm{~L}$ of distilled water. Conductivity and $\mathrm{pH}$ were $700 \mu \mathrm{S}$ and 7.4-7.5, respectively. Tadpoles were kept at a density of 30-50 animals L-1, at $24^{\circ} \mathrm{C}$ and fed daily with spirulina. All procedures complied with the standards of the ethical commission of the University of Barcelona. Xenopus tropicalis tadpoles (developmental stages 44-48 according to Nieuwkoop and Faber) ${ }^{14}$ were paralyzed in $0.23 \mathrm{mM}$ of Pancuronium dibromide solution (PCD) (Merck, Cat no. P1918) for 10 minutes and placed into a 48 -well plate ( $\mathrm{Nunc}^{\mathrm{TM}}$ Microwe $^{\mathrm{TM}}{ }^{\mathrm{M}}$ ) with $200 \mu \mathrm{L}$ of $0.1 \mathrm{X}$ solution of $\mathrm{MMR}^{-\mathrm{CaCl}_{2}}$ (referred as BS from now on). PCD was preferred to tricaine because of its higher cardiac tolerability and nonUV dependent effects. ${ }^{15}$

Cardiac activity measurements. Video recordings of tadpole hearts were performed using a Nikon Eclipse TS100 microscope equipped with an OptixCam Summit Series OCS-D3K2-5 camera, which substantially improved the resolution of the previously reported setup. ${ }^{16}$ In order to prevent unintended cis-to-trans isomerisation of photoswitchable compounds, the microscope top-down light pathway was dimmed with a red plastic filter, which could be placed or removed during experimentation. Video recordings were acquired using the ToupView software, enhancing visual contrast to improve cardiac imaging and video streams were converted to the $\mathrm{AVI}$ format. Recordings were briefly interrupted during compound addition and changes of illumination conditions. Video information and data analysis were extracted and executed with custom scripts based on Image $\mathrm{J}^{17}$ for AVI files analysis and subsequently converted to the TXT format for R software analysis. ${ }^{18}$

The illumination protocol established for control and treatment video recordings applied the following procedure: one minute dimmed red light $\left(650 \mathrm{~nm}, 34.0 \mathrm{~W} \cdot \mathrm{m}^{-2}\right)$, three minutes under UV $\left(365 \mathrm{~nm}, 2.3 \mathrm{~W} \cdot \mathrm{m}^{-2}\right)$ due to the required exposure time for a complete trans-to-cis isomerisation, two minutes dimmed red light and one minute under visible light $\left(455 \mathrm{~nm}, 169.8 \mathrm{~W} \cdot \mathrm{m}^{-2}\right)$ for cis-to-trans back isomerisation.

Tadpoles $(n=4)$ were firstly paralyzed with PCD as previously described, placed in the BS and video recorded under the established protocol of illumination in the absence of PAI to monitor the effect of the light on cardiac activity and verify control conditions. Afterwards, animals were placed into a $10 \mu \mathrm{M}$ PAl solution and underwent the same protocol of illumination to observe the light-dependent effects of the drug.

Data analysis and statistics. Heart beating movies were converted to a linear signal by selecting a region of interest displaying large periodic variations corresponding to heart movements, and calculating the corresponding grey scale level as a function of time (Figure 3abcd). The cardiac rate (beats. $\mathrm{s}^{-1}$ ) was calculated from this linear signal from the number of maxima every $15 \mathrm{~s}$ (red plots in Figure 3e). To statistically compare between different illumination periods and drug conditions, the cardiac rate was calculated from the last 30 $s$ of every period. The stability of cardiac rhythm in each period was quantified with a unit-less variability score as the number of video frames between heartbeats. High scores correspond to longer periods with asynchronic or arrested cardiac activity. Perfectly steady rate in the absence of PAI yields a variability score of 8 (Figure S6.2).

Statistical analyses were carried out with a two-way repeated measures ANOVA with uncorrected Fisher's Least Significant Differences (LSD) test in which two main factors (heart beats per second, $10 \mu \mathrm{M}$ of PAI) and their interaction (heart beats per second $\times 10 \mu \mathrm{M}$ of PAI) were included (Figure 3f). 


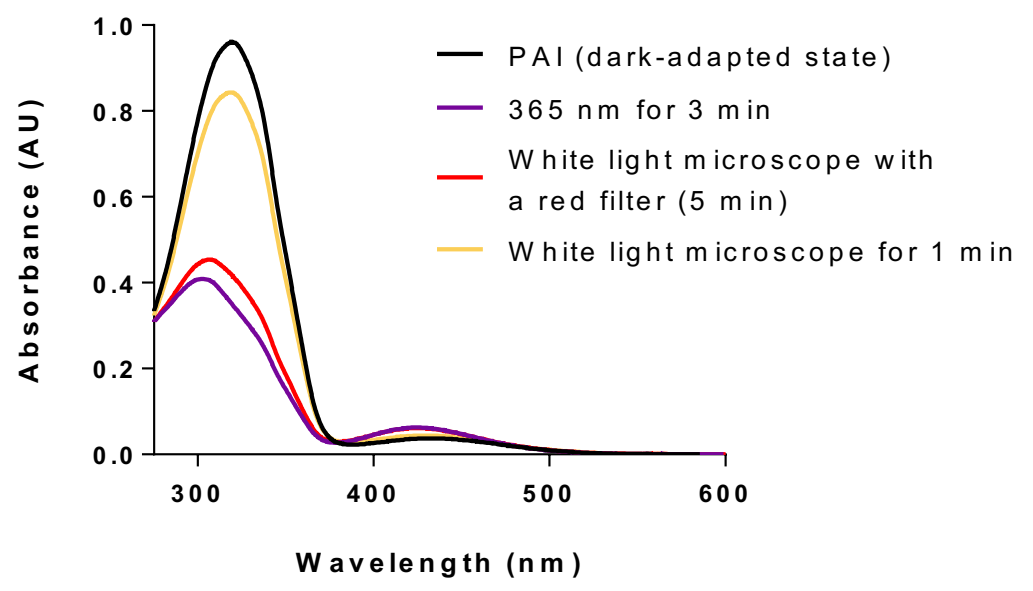

Figure S6.1. Validation of the photochromic behavior of PAI under the illumination conditions used for our in vivo experiments in $X$. tropicalis tadpoles. PAl could be effectively isomerized to cis under illumination with $365 \mathrm{~nm}$ light (external source) and back-isomerized to trans using unfiltered microscope white light (100\% intensity), whereas the cis-enriched photostationary state could be satisfactorily maintained when the microscope light was filtered with a common red polycarbonate filter.

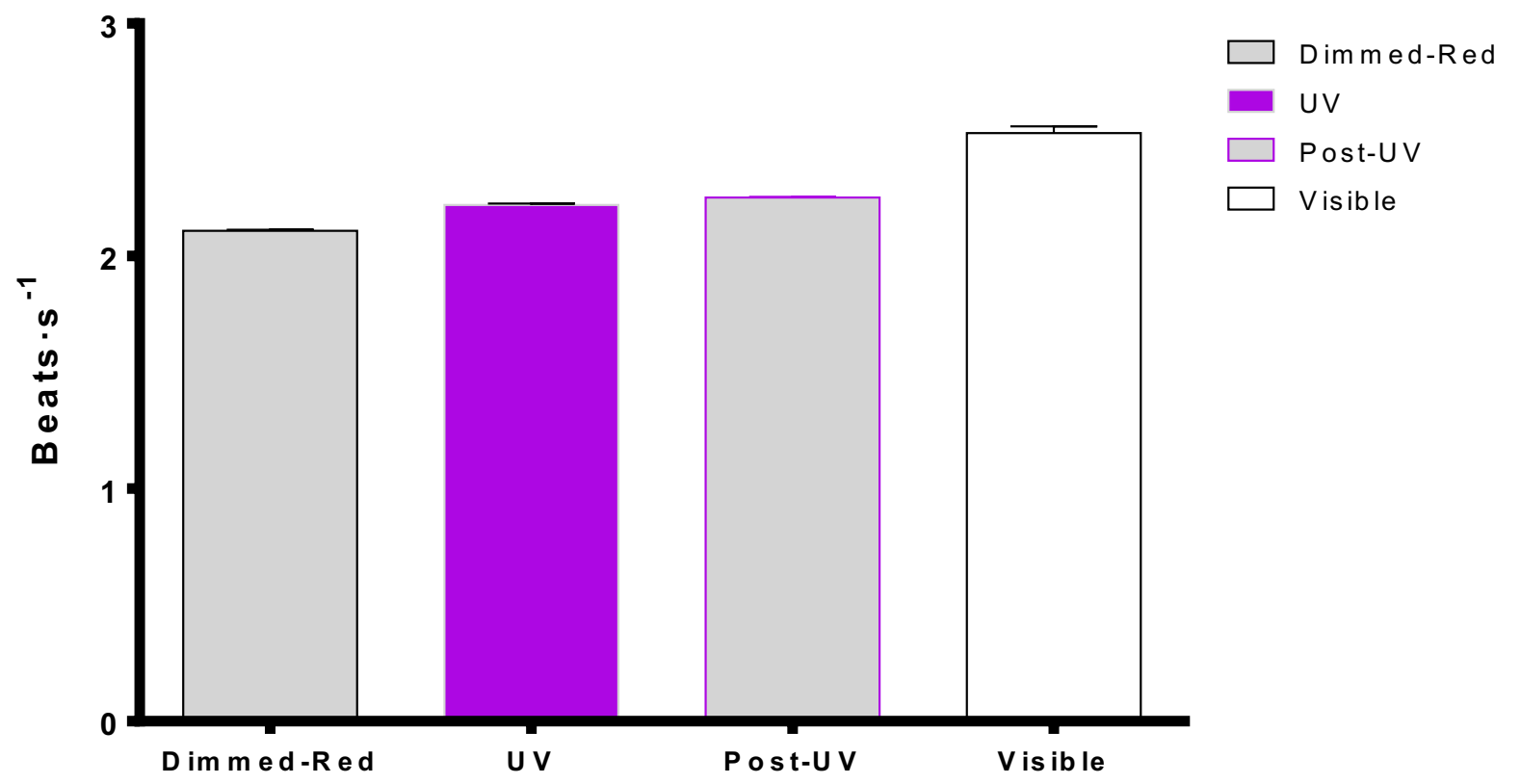

Figure S6.2. Cardiac activity (beats per second) recorded under different conditions of illumination in absence of PAI (control experiment). Error bars represent SEM $(n=4)$. 


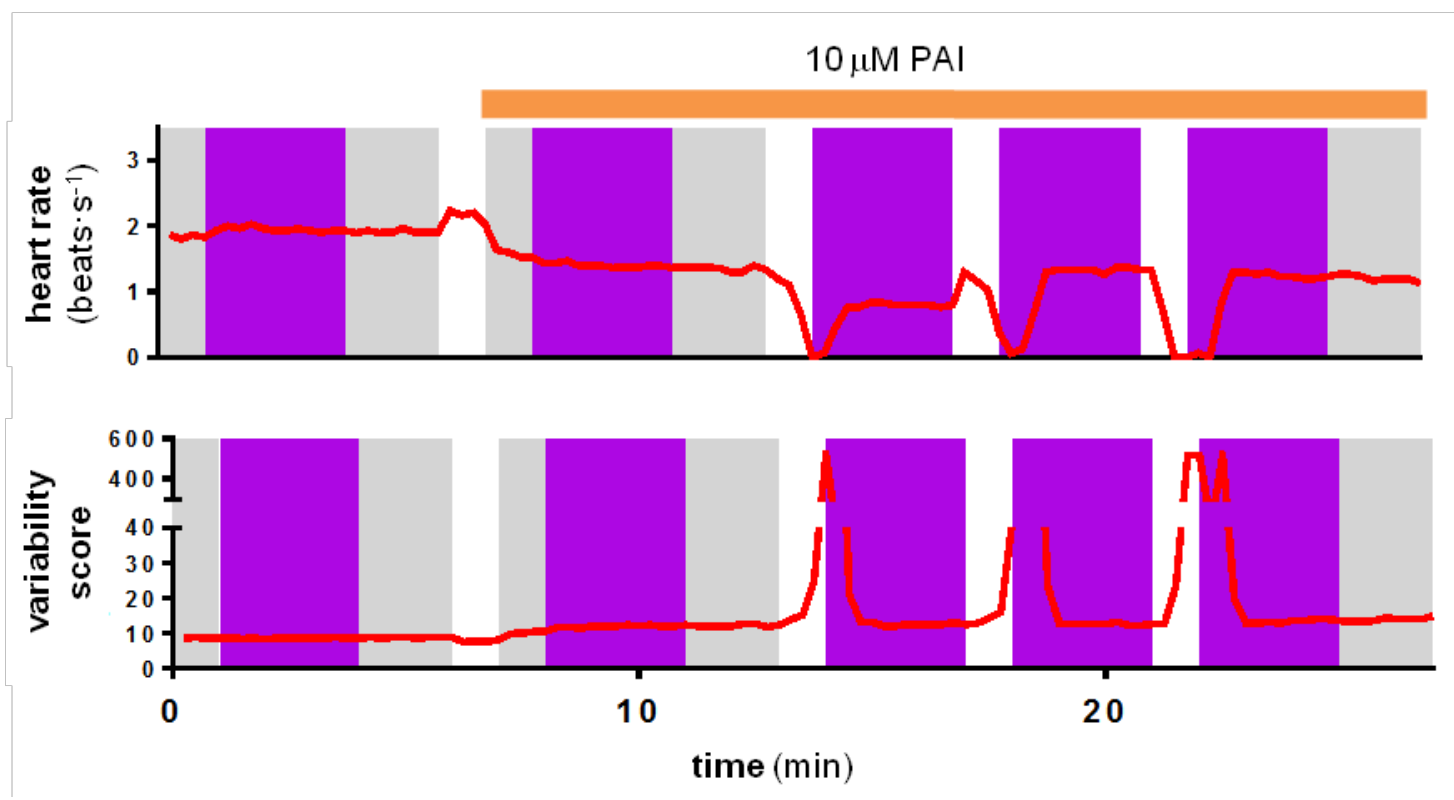

Figure S6.3. Example trace of cardiac rate from one animal in Figure 3 (top) and corresponding variability score calculated as the number of video frames between heartbeats (averaged every $15 \mathrm{~s}$ ). Although the first exposure to 10 $\mu \mathrm{M}$ trans-PAI did not immediately reduce the heart rate of this animal, subsequent cycles of UV/white light in the presence of PAI reversibly switched the heartbeat on and off. Reduced heart rate was associated with longer periods displaying unstable, asynchronic cardiac activity and thus a higher variability score. 


\section{In vivo experiments in rats}

\subsection{Materials and methods}

In vivo effects of PAl in both configurations (trans and cis) were further tested in male Wistar rats (400-500 g) under inhaled anesthesia (isoflurane $1.5 \%$ ) and maintained at $37 \pm 0.3{ }^{\circ} \mathrm{C}$ with a homothermic pad (Kent Scientific, Torrington, CT, US). All animals had a continuous electrocardiogram (ECG) obtained (lead II) and recorded for later offline analyses (PowerLab and LabChart v.8.1.2, ADInstruments, Colorado Springs, CO, US). Analyses were performed in a blinded manner.

Nine rats were randomly assigned to receive cumulative doses of either predominantly trans- ("trans" group, $n=5$ ) or cis-isomer ("cis" group $n=4$ ) PAI. A single stock solution was used for all experiments, and dilutions were prepared just prior to each experiment. In the "cis" group, a vial containing $1 \mathrm{~mL}$ of PAl solution was irradiated with UV-light lamp (365 nm) in a custom-made closed chamber for 5 minutes, and thereafter administered intraperitoneally in dark conditions. Two animals (one for each "cis" and "trans" groups) were initially used to delimitate the effective dose range, which was found to be in the range of $100 \mathrm{nM} / \mathrm{kg}-100$ $\mu \mathrm{M} / \mathrm{kg}$ (results not shown). Subsequently, the following PAl doses were intraperitoneally administered at 7minute intervals in the remaining rats: $100 \mathrm{nM} / \mathrm{kg} ; 300 \mathrm{nM} / \mathrm{kg} ; 1 \mu \mathrm{M} / \mathrm{kg} ; 3 \mu \mathrm{M} / \mathrm{kg} ; 10 \mu \mathrm{M} / \mathrm{kg} ; 30 \mu \mathrm{M} / \mathrm{kg} ; 100$ $\mu \mathrm{M} / \mathrm{kg}$.

The heart rate (beats. $\mathrm{min}^{-1}$ ) and the PR interval (ms) were measured offline to assess the parasympathetic effect of both PAI isomers (LabChart v.8.1.2, ADInstruments, Colorado Springs, CO, US). A one-minute recording (from minute $5^{\prime} 30^{\prime \prime}$ to minute $6^{\prime} 30^{\prime \prime}$ after each dose administration) of stable ECG was analyzed. Heart rate and the PR interval were automatically determined, manually reviewed for accuracy, and modified if needed. Second degree Wenckebach atrio-ventricular block and subsequent complete block occurred in one rat receiving the $30 \mu \mathrm{M} / \mathrm{kg}$ dose and one rat receiving the $100 \mu \mathrm{M} / \mathrm{kg}$ dose, and were excluded from PR interval measurements. Results are shown as difference to the baseline value $(\Delta)$.

In order to test that parasympathetic activity was driving heart rate and PR-interval changes, and to assess its reversibility, atropine (two $1 \mathrm{mg}$ doses separated by 5-7 minutes) was administered to one rat per group. A representative profile of a full experiment is shown in Figure S7.1.

Data analysis and statistics. In vivo data is shown in boxplots. Because some rats died after the administration of high doses of the active isomer trans-PAl, a maximum effect asymptotic value was not reached and a formal dose-response curve could not be built. Therefore, analyses were carried out with a two-way ANOVA in which two main factors (Isomer, Dose) and their interaction (Isomer $x$ Dose) were included. In the case of a significant interaction, pairwise comparisons (Isomer effect at each Dose) were performed with the LSD test. 
$\underline{\text { Heart rate }}$

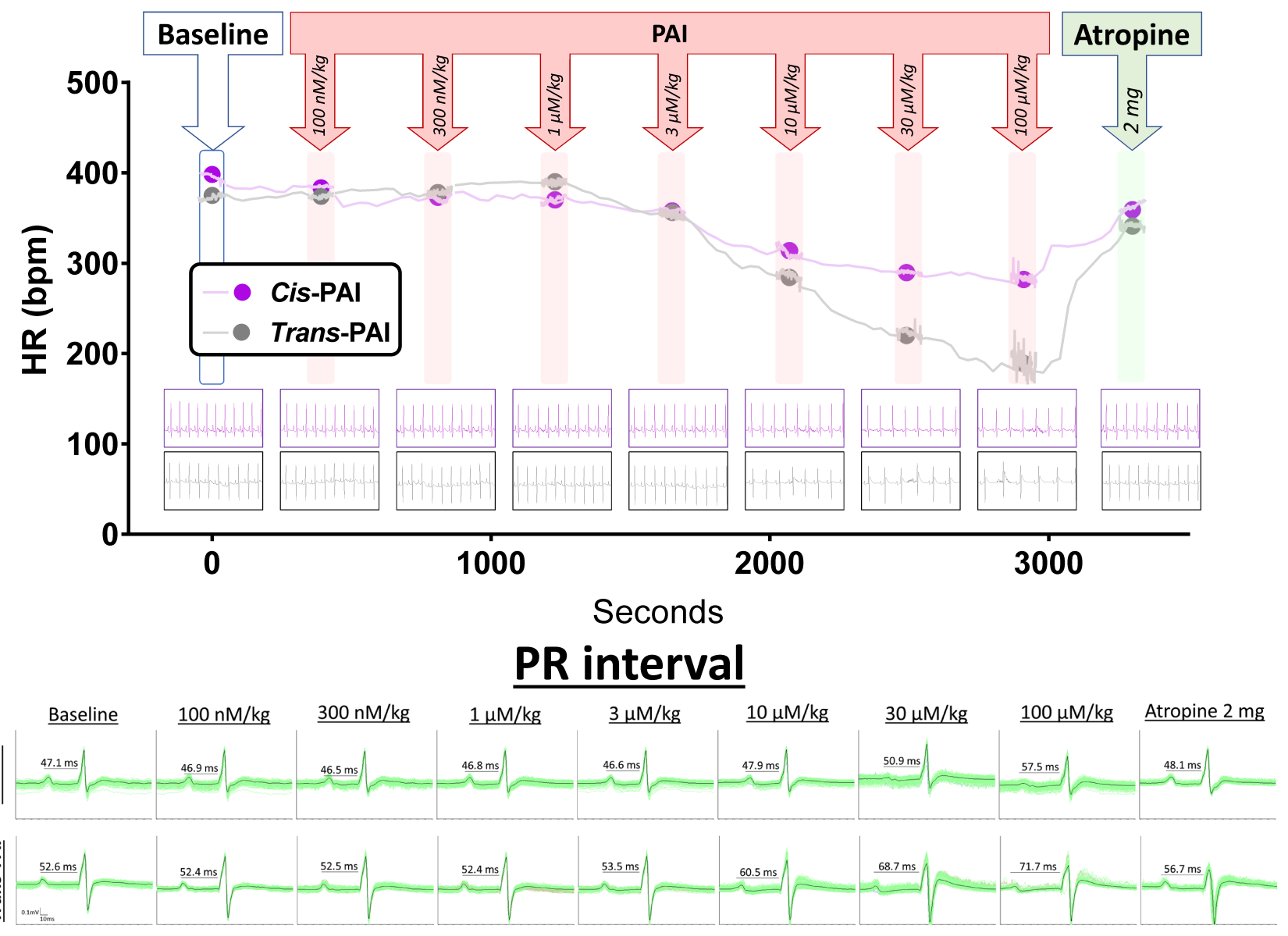

Figure S7.1. Representative profile of the heart rate (upper panel) and the PR interval (lower panel) in two rats receiving increasing doses of PAI (trans or cis form), and atropine. Heart rate is averaged every second in shadowed areas in the upper panel; in between doses, heart rate is averaged every 30 seconds. 


\section{Additional references}

(1) Dallanoce, C.; Conti, P.; De Amici, M.; De Micheli, C.; Barocelli, E.; Chiavarini, M.; Ballabeni, V.; Bertoni, S.; Impicciatore, M. Synthesis and Functional Characterization of Novel Derivatives Related to Oxotremorine and Oxotremorine-M. Bioorg. Med. Chem. 1999, 7 (8), 1539-1547.

(2) Kloeckner, J.; Schmitz, J.; Holzgrabe, U. Convergent, Short Synthesis of the Muscarinic Superagonist Iperoxo. Tetrahedron Lett. 2010, 51 (27), 3470-3472.

(3) Hoang, L. T. M.; Ngo, L. H.; Nguyen, H. L.; Nguyen, H. T. H.; Nguyen, C. K.; Nguyen, B. T.; Ton, Q. T.; Nguyen, H. K. D.; Cordova, K. E.; Truong, T. An Azobenzene-Containing Metal-organic Framework as an Efficient Heterogeneous Catalyst for Direct Amidation of Benzoic Acids: Synthesis of Bioactive Compounds. Chem. Commun. 2015, 51 (96), 17132-17135.

(4) Velema, W. A.; van der Toorn, M.; Szymanski, W.; Feringa, B. L. Design, Synthesis, and Inhibitory Activity of Potent, Photoswitchable Mast Cell Activation Inhibitors. J. Med. Chem. 2013, 56 (11), 4456-4464.

(5) Deshpande, S.; Gadilohar, B.; Shinde, Y.; Pinjari, D.; Pandit, A.; Shankarling, G. Energy Efficient, Clean and Solvent Free Photochemical Benzylic Bromination Using NBS in Concentrated Solar Radiation (CSR). Sol. Energy 2015, 113, 332-339.

(6) Disingrini, T.; Muth, M.; Dallanoce, C.; Barocelli, E.; Bertoni, S.; Kellershohn, K.; Mohr, K.; De Amici, M.; Holzgrabe, U. Design, Synthesis, and Action of Oxotremorine-Related Hybrid-Type Allosteric Modulators of Muscarinic Acetylcholine Receptors. J. Med. Chem. 2006, 49 (1), 366-372.

(7) Gomeza, J.; Mary, S.; Brabet, I.; Parmentier, M. L.; Restituito, S.; Bockaert, J.; Pin, J. P. Coupling of Metabotropic Glutamate Receptors 2 and 4 to G Alpha 15, G Alpha 16, and Chimeric G Alpha Q/i Proteins: Characterization of New Antagonists. Mol. Pharmacol. 1996, 50 (4).

(8) Kruse, A. C.; Ring, A. M.; Manglik, A.; Hu, J.; Hu, K.; Eitel, K.; Hübner, H.; Pardon, E.; Valant, C.; Sexton, P. M.; et al. Activation and Allosteric Modulation of a Muscarinic Acetylcholine Receptor. Nature 2013, 504 (7478), 101-106.

(9) Antony, J.; Kellershohn, K.; Mohr-Andrä, M.; Kebig, A.; Prilla, S.; Muth, M.; Heller, E.; Disingrini, T.; Dallanoce, C.; Bertoni, S.; et al. Dualsteric GPCR Targeting: A Novel Route to Binding and Signaling Pathway Selectivity. FASEB J. 2009, 23 (2), 442-450.

(10) Bock, A.; Bermudez, M.; Krebs, F.; Matera, C.; Chirinda, B.; Sydow, D.; Dallanoce, C.; Holzgrabe, U.; De Amici, M.; Lohse, M. J.; et al. Ligand Binding Ensembles Determine Graded Agonist Efficacies at a G Protein-Coupled Receptor. J. Biol. Chem. 2016, 291 (31), 16375-16389.

(11) Pettersen, E. F.; Goddard, T. D.; Huang, C. C.; Couch, G. S.; Greenblatt, D. M.; Meng, E. C.; Ferrin, T. E. UCSF Chimera-A Visualization System for Exploratory Research and Analysis. J. Comput. Chem. 2004, 25 (13), 1605-1612.

(12) Morris, G. M.; Huey, R.; Lindstrom, W.; Sanner, M. F.; Belew, R. K.; Goodsell, D. S.; Olson, A. J. AutoDock4 and AutoDockTools4: Automated Docking with Selective Receptor Flexibility. J. Comput. Chem. 2009, 30 (16), 27852791.

(13) Dallakyan, S.; Olson, A. J. Small-Molecule Library Screening by Docking with PyRx. In Methods in molecular biology (Clifton, N.J.); 2015; Vol. 1263, pp 243-250.

(14) Nieuwkoop P., F. J. Normal Table of Xenopus Laevis (Daudin): A Systematical \& Chronological Survey of the Development from the Fertilized Egg till the End of Metamorphosis; 1994.

(15) Bartlett, H. L.; , Scholz, T. D.; Lamb, F. S.; And; Weeks, D. L. Characterization of Embryonic Cardiac Pacemaker and Atrioventricular Conduction Physiology in Xenopus Laevis Using Noninvasive Imaging. J. Am. Coll. Cardiol. 2004, 37 (2), A379-A452.

(16) Eckelt, K.; Masanas, H.; Llobet, A.; Gorostiza, P. Automated High-Throughput Measurement of Body Movements and Cardiac Activity of Xenopus Tropicalis Tadpoles. J. Biol. Methods 2014, 1 (2), 9.

(17) Schindelin, J.; Arganda-Carreras, I.; Frise, E.; Kaynig, V.; Longair, M.; Pietzsch, T.; Preibisch, S.; Rueden, C.; Saalfeld, S.; Schmid, B.; et al. Fiji: An Open-Source Platform for Biological-Image Analysis. Nature Methods. 2012, pp 676682.

(18) R: A language and environment for statistical computing. Vienna, Austria: R Foundation for Statistical Computing; 2016. 
Control of cardiac function in vivo with a light-regulated dru... (4.50 MiB) view on ChemRxiv • download file 
Other files

Movie S1.avi (4.37 MiB)

view on ChemRxiv • download file 